\title{
LA BIBLIOTECA POSTRIMERA DE CARLOS V EN ESPAÑA: LAS LECTURAS DEL EMPERADOR*
}

por

JosÉ LuIS GONZALO SÁNCHEZ-MOLERO

Instituto de Historia, CSIC

RESUMEN: Este artículo aborda la reconstrucción de la biblioteca que el emperador Carlos $V$ tuvo en España, tanto en el monasterio de Yuste como en el castillo de Simancas, donde él guardó parte de sus pertenencias. El autor localiza los libros del Emperador por medio de los inventarios de sus bienes y de la biblioteca de Felipe $I I, y$ Los catálogos antiguos de la Real Biblioteca de El Escorial; e identifica algunos de los libros perdidos. Por último, el autor realiza un estudio de los perfiles dinástico, personal y religioso de Carlos $V$ a través de sus lecturas.

Palabras clave: Carlos V. España. Biblioteca. Siglo XVI.

ABSTRACT: This anticle addresses the reconstruction of the library boldings that the emperor Charles $V$ bad in Spain, both in the monastery of Yuste and in the castle of Simancas, where be kept part of bis belongings. The author locates the books of the Emperor by means of the inventories of bis goods and of the Pbilip II's library, and the old catalogs of the Royal Library of the Escorial; and be identifies some of the lost books. Lastly, the autbor carries out a study of the dynastic, personal and religious appects of Carlos $V$ througb bis readings.

KEY wORDs: Charles V. Spain. Library. $16^{\text {th }}$ Century.

En los pintores historicistas y románticos del siglo XIX produjo una gran atracción el tema del retiro del césar Carlos en Yuste. Si nos detenemos en los múltiples cuadros que se pintaron entonces, nos sorprenderá encontrar un ele-

- Este artículo forma parte de nuestro proyecto de investigación postdoctoral «Las bibliotecas reales de los Austrias en la España del siglo XVI. Estudio hiscótico y catalogaciónm, financiado por la Fundación Caja Madrid y dirigido por el doctor Alfredo Alvar Ezquerra (CSIC).

Hispania, LX/3, núm. 206 (2000)911-944 
mento que casi aparece en todas las composiciones: los libros. En una mesa al lado del monarca, en sus manos, o en unos anaqueles tras la escena principal, figuran unos volúmenes, encuadernados en pergamino o cuero labrado, que son siempre representación gráfica del papel de la lectura, verdadero descanso del viejo emperador en aquel monasterio extremeño. Unos libros que fueton el testigo mudo tanto de las últimas añoranzas, como de las más íntimas angustias de aquel verdadero "caballero determinado", antes de su encuentro con "Atropos", si seguimos la metáfora de Olivier de la Marché. Conocemos el inventario de sus libros, realizado en Yuste a su muerte, y sobre esta lista, publicada en numerosas ocasiones desde mediados de siglo XIX, los biógrafos del monarca han vuelto una y otra vez. Pero como señala $\mathrm{M}^{\mathrm{a}}$ Isabel González, en su inventario de bibliotecas españolas del siglo XVI, no se han identificado los volúmenes que integraban, en su conjunto, esta pequeña librería imperial, ni se han localizado de manera fehaciente los mismos ${ }^{1}$. A esta tarea se aboca este artículo, con el objetivo de reconstruir, a través de los libros que Carlos $\mathrm{V}$ escogió para llevar a España, un retrato de su «mentalidad» en los últimos años de su vida.

Antes de iniciar esta tarea se hace necesario realizar algunas precisiones, por un lado sobre el perfil cultural, y bibliófilo, del César, y por otro lado sobre las características de los libros que dejó a su muerte. Con respecto al primer punto, debe advertirse que Carlos V no fue un hombre demasiado inclinado al cultivo de las letras. Si bien a su alrededor se desarrolló un intenso humanismo áulico, lo cierto es que el emperador no exhibió el interés personal por la cultura que, por ejemplo, sí encontramos en sus hermanos María, reina viuda de Hungría, y Fernando, rey de Romanos. Las razones de esta carencia parece que deben buscarse en el escaso nivel de sus estudios de latinidad, motivado por la ausencia en su niñez de un verdadero programa pedagógico, que hubiera hecho crecer en él un interés pleno por las cuestiones culturales. En consecuencia, sus aficiones como lector tenían un umbral muy personal. No encontraremos, pues, en su biblioteca, numerosos autores griegos y latinos, ni a humanistas renacentistas, sino obras que respondían a sus apetencias religiosas y políticas, y que, por tanto, eran más contemporáneas que clásicas. Esta circunstancia, sin duda, permite entender de antemano la -en apariencia - escasa calidad de sus libros, siempre si la ponemos en comparación con las colecciones librarias de otros miembros de su familia. Pero al mismo tiempo, esto tiene una ventaja: es una biblioteca personal. Nos habla de su poseedor más que las librerías de sus hermanos, o de su hijo Felipe ${ }^{2}$, que sin ser más impersonales, lo cierto es que responden a criterios más propios del biblibfilo, ansioso por contener entre sus

1 HeRnANDEZ GoNZÁlez, $M^{2}$ Isabel: «Suma de inventarios de bibliotecas del siglo XVI (1501-1560)m, en El Libro Antiguo Español, IV, pp. 425-426.

2 GonZalo SÁNCHEZ-MOLero, José Luis: La «Libreria rica* de Felipe II. Estudio Histórico y catalogación, Madrid, Ediciones Escurialenses, 1998.

Hispania, LX/3, núm. 206 (2000) 911-944 
libros to mejor de todos los autores, lenguas y disciplinas, que por una lectura detenida de los mismos.

El primer inventario de la biblioteca de Carlos V es de 1517, en una descripción de los bienes que trajo consigo en su primer viaje a España. Por entonces gustaba de leer libros de historia, como Las Décadas de Tito Livio, y una Crónica de Francia, de Monstrelet, así como libros de caballerías, entre los que aparecen citados el Giron le Courtois, las Crónicas de Jerusalén, manuscritas, o el Olivier de Castilla y el Huon de Burdeos. También tenía algunos libros de devoción, como dos Pasiones, y el Tratado de las últimas cosas ${ }^{3}$. El siguiente inventario que conocemos data de $1536^{4}$. En él descubrimos una gran cantidad de códices y manuscritos ricamente encuadernados y miniados, pero que el César había heredado en gran parte de los duques de Borgoña. No eran «sus» libros, sino los de María de Borgoña, Margarita de York, Felipe el Hermoso, o Margarita de Austria. Es más, Carlos V, aunque apreciaba su valor tanto cultural como simbólico, no se sirvió de esta biblioteca, que siempre permaneció en Bruselas. Fueron su tía, la archiduquesa Margarita, y su hermana, la reina María, gobernadoras de los Países Bajos', quienes se cuidaron de su conservación. Más que de una biblioteca de Carlos V, debería hablarse de una biblioteca de Borgoña.

El César, sin embargo, tenía sus propios libros, y es de suponer, tanto por sus continuados viajes, como por los múltiples regalos que en forma libraria un monarca de su categoría recibió, que esta biblioteca sería compleja y rica. Una de las fuentes que más información aporta en este sentido es la amplísima correspondencia de la época. En ella se nos proporcionan algunas pistas. Sabemos, por ejemplo, que en 1524 Cornelio Schepper, secretario del destronado Cristián II, rey de Dinamarca, llegó a Castilla para entrevistarse con el César, ocasión que aprovechó para hacerle entrega de su tratado latino en defensa del danés, cuñado de Carlos ${ }^{6}$. De igual manera, en 1533 el humanista Calvete de

3 Foronda y Aguilera, Manuel: allos mayordomos de casa y boca de Carlos V", Discurso leido ante la $R A H$, Madrid, 1916, p. 20. Citado por Alfredo Alyar EzQuerra, El César Carlos. De Gante a Yuste, Madrid, Banco Bilbao Vizcaya, 1998, p. 41.

4 MICHELANT, M: «Inventaire des joyaux, omaments d' eglise, vaisselles, tapisseries, livres, tableaux, etc., de Charles-Quint, dressé à Buxxelles au mois de mai 1536*, en Compte-rendu des séancer de la Commission Royale d'Histoire ou recuil de ses bulletins, $3^{2}$ serie, $\mathrm{t}$. XII, Bruselas, $1872, \mathrm{p} .199 \mathrm{y}$ ss.

3 Sobre las bibliotecas de estas dos mujeres, tía y hermana de Carlos V, vid. DeBAE, M.: La bibliothìque de Marguerite d'Autriche. Essai de reconstitution d'après l'inventaire de 1523-1524, LovainaParís, 1995; y Lemalre, Claudine: «La bibliothèque des imprimés de la reine Marie de Hongrie régente des Pays-Bas, 1505-1558", Bibliothèque d'Humanisme et Renaissance. Travaux et Documents, LVIII (1996), pp. 119-139.

6 Juan Dantisco al rey Segismundo I de Polonia (Madrid, 7-feb-1525). En FonTÁN, Antonio y AXER, Jerzy (eds.): Españoles y polacos en la Corte de Carlos V. Cartas del embajador Juan Dantisco, Madrid, Alianza Universidad, 1994, p. 167. Sin duda, se refiere a las dos apologías publicadas en 1524, en Witternberg, por Schepper, Contra se Lubicensium articulor, quibus suscepto aduersus eum belli rationem prescribunt ... responsio, y Ad duas epistolas quibus rationem belli aduersus illum suscepti... Holsatiace Dux D. Fridericus... responsio. 
Estrella entregó al monarca un ejemplar manuscrito de sus epigramas latinos ${ }^{7}$, y en 1543 Sebastián de la Cruz le envió el De Revolutionibus orbium Coelestium, de Copérnico, con la excusa de que aquel era "amador de la materia»8. Todavía en 1551 el arzobispo Juan Martínez de Silíceo remitió a Granvela unos ejemplares de su De divino nomine Jesus, para que hiciera entrega de uno al emperador ${ }^{9}$. Es al mismo tiempo muy abundante la bibliografía sobre los códices miniados, libros de horas, misales, en particular de las escuelas de Gante y Brujas, hechos para el emperador, y que por la belleza de sus iluminaciones han merecido detenidos estudios ${ }^{10}$. El propio monarca encargó alguna de estas obras, u otras, como cierto "libro de las armas de todos los grandes de españa» ${ }^{11}$, que en 1527 encomendó a su pintor Jacob van Laeth.

Ninguna de estas obras, sin embargo, llegó a España. En 1545 se realizó un nuevo inventario de la cámara de Carlos V, incluida su biblioteca ${ }^{12}$, pero lo más probable es que los libros que la integraban se perdieran en Innsbruck, tras la famosa huida del monarca en 1552, amenazado por las tropas de la liga protestante. Mauricio de Sajonia se apoderó de buena parte de la cámara imperial, abandonada en la ciudad, y sólo unos años más tarde se avino a entregar

7 LÓPEZ DE TORO, José: «El panegírico de Carlos V por J. C. Calvete de Estrella». Separata del Boletín de la Real Academia de la Historia, 143. Cuaderno 2, Madrid, ediciones Maestre, 1958, pp. 99-145. Al hacer un retrato físico y espiritual de Carlos V, Calvete resalta el fulgor de sus ojos y su resplandeciente cara como el sol; y añade: «Yo tuve ocasión de comprobarlo cuando arrodillado ante tí en Monzón, ofrecí a tu Majestad el libro de los Epigramasn, (pp. 115-116).

8 Sebastián Cruz a Carlos V, AGS (Archivo General de Simancas), Estado, leg. 499, fol. 2.

9 Carta de Juan Martínez de Silíceo a Antonio Perrenot de Granvela: «Reuerendisimo señor. A vuestra señoria embio ciertas obras en vn volumen pequeño las quales he conpuesto en el poco tiempo que me sobra. Creo que v. s. las podra mejor corregir que otro, y si le pareçiere que a su mag. se den, a quien dedicamos el libro primero del nombre diuino de Ieshus hazerlo ha, y si no le pareçieren ser dignas, de presentarsele, tretenerlas ha y escrevirame su pareçer açerca de todo: que lo tendre yo, como de verdadero amigo que se me ama, y esto selo porque yo le amo, y no se engañan los coraçones de los hombres principalmente los bien ynstituydos en el amar. Nuestro Señor la $\mathrm{Rm}^{2}$ persona de v. s. haya bien anenturada. En Toledo a XxvIII de nouiembre de 1550". BNM (Biblioteca Nacional de Madrid)., Ms. 7.915, carta 89.

10 Durrieu, Paul: La Miniature Flamande au temps de la Cour de Bourgogne (1415-1530). Ouvrage publié aver le concouts de l'Académie des inscriptions et Beller-Lettres. El estudio, sin embargo, más reciente y completo es de un español: DOCAMPo, Javier: «Imagen religiosa y devoción privada: los libros de oraciones de Carlos V", en IX Jornadas de Arte. El arte en las cortes de Carlos V y Felipe II, Madrid, CSIC, 1999, pp. 215-224.

If Cuentas de pagos a criados de Carlos V, entre ellos el «maestre Jacques banlaten pintor de su mag»: «En Burgos a XXIII de nouiembre de DXXVII, veynte ducados de oro para en quenta de vn libro que hizo para su mag. De las armas de todos los grandes de españa», y debajo: «En xxiiii del mes de diziembre al dicho para el efecto susodicho quinze ducados». AGS, CSR (Casa y Sitios Reales), leg. 38054 , sin foliar.

12 Bruselas, Archives Générales du Royaume, État et Audience, leg. 1193. Se citan libros que comprendían tanto códices miniados como ejemplares impresos, algunos de ellos bellamente encuadernados. 
gran parte de lo saqueado al rey Fernando. Ésta es la razón de que en la Österreichisch Nationalbibliothek, de Viena se conserven libros que pertenecieron al monarca, como su Breviario infantil, u obras que, a él dedicadas, llegaron hasta Austria por esta vía. Es el caso del Aquatilium animalium bistoriae, de Hipólito Salviano ${ }^{13}$, un tratado sobre los peces y animales acuáticos, magníficamente encuadernado para Carlos V; o del rico manuscrito de las Stanzen, de Eurialo $\mathrm{d}^{\prime}$ Ascoli ${ }^{14}$. En Viena se conserva también un ejemplar del libro, antes citado, del arzobispo Silíceo, y que, como decimos, probablemente fue el remitido a Carlos V en $1551^{15}$.

Sin embargo, no todos los libros de Carlos V se abandonaron e Innsbruck. Sus mozos de cámara debieron recoger algunas arcas con lo más valioso, o cuando menos, lo que era de uso más diario del César, como sus libros litúrgicos, o sus lecturas más cotidianas. Salvada así del saqueo, la corte imperial se encaminó con esta librería hasta Bruselas, lugar donde el César, profundamente deprimido, (en especial tras el fracaso del sitio de Metz), empezó a configurar la biblioteca que finalmente Felipe II encontrará en Yuste, y que, como indicamos, al principio, es la que más atención ha suscitado entre los biógrafos del monarca. El inventario que conocemos de estos libros, los "postreros" del emperador, se conserva en el Archivo General de Simancas, en el legajo 1145 de la sección de Contaduría Mayor de Cuentas, $1^{2}$ época, y se ha publicado en varias ocasiones. Quien primero manejó este inventario fue Tomás González, director del mismo Archivo, autor de una Estancia, retiro y muerte del Emperador Carlos $V$ en el monasterio de Yuste, obra manuscrita que Gachard encontró en la Biblioteca Nacional de París, y que en 1854 le condujo a solicitar una copia del inventario manejado por González. Gachard lo incluyó así de manera completa en su Retraite et mort de Charles Quint au monastère de Yuste: Lettres inédites (Bruselas, 1854, 1855, 3 vols.). Francois M. A. Mignet también lo manejó en su obra Charles Quint, son abdica-

13 SAlviano, Hippolito: Aquatilium animalium bistoriae, Romà, Salvianus, 1554. ÖNB (Österreichisten Nationalbibliothek), 65. P. 42 (ES 99). Encuadernación renacentista italiana. En el centro, dentro de una estrella seis puntas, placa de dos tenantes con un escudo imperial esmaltado en colores, en el interior, y hierro de corona imperial encima.

ti d' Ascoli, Eurialo: Stanzen. Códice sobre pergamino en italiano, iluminado por Giulio Clovio entre $1535 \circ 1543.170 \times 105 \mathrm{~mm}$. ÖNB, Cod. 2660. En la tapa dos columnas de Hércules, de cuyos capiteles se suspende un hierro de la corona imperial, y debajo la leyenda en letras doradas: «PLVS VLTRE.»; y en la contratapa un condo esmaltado con un águila bicéfala.

is Laannis Martinit Silicei Archiepiscopi Toletani de diuino nomine lesus, per nomem tetragrammata significato liber vnus. Cui accessere in orationem dominicam, salutationemque Angelicam, Expositiones duae ab eadem autore nunc primum typis excussae, Toledo, Juan Ferrer, 1550. $8^{\circ}$. La cubierta de este libro es idéntica a la del ejemplar de Felipe II, conservado en la Real Biblioteca del Escorial, RBME (Real Biblioteca del Monasterio del Escorial), 47-VI-8. La encuadernación del libro ha sido reproducida por Otto MAZAL, en Europäische Einbankunst aus Mittelalter und Neuzeit. Ausstellung der Handscbriftenund Inkunabelsammlung der Österreichiscben Nationalbiblioshek. Prunksaal 22-Mai. - 26. Oktober 1990, Graz 1990, pp. 83-84, $\mathrm{n}^{\circ}$ 137. Signatura: 32. Mm. 48 (ES 152). Lámina en blanco y negro en pp. posteriores. 
tion, sa retraite et son séjour et sa mort au monastère de Yuste (París, 1852), y con posterioridad han sido varios los autores que lo han utilizado's.

Todos ellos, sin embargo, repiten una misma lista de libros, apenas una treintena de títulos dispares, que sin embargo, no constituyen sino una parte de la biblioteca que Carlos $\mathrm{V}$ trajo consigo a España, ya que el emperador envió al castillo Simancas otro grupo de libros. En 1891 Rudolf Beer publicó los títulos de algunos de éstos ${ }^{17}$, mas no copió la lista entera, quizá porque la fuente que manejó (el citado legajo 1145) era incompleta. Lo mismo hicieron Miguel Morán y Fernando Checa ${ }^{18}$. El inventario de los bienes que aquí manejamos se conserva en la sección de Casa y Sitios Reales, legajo 72, y sí presenta en su integridad la lista de esta parte de los libros catolinos. En la compleja acción de inventariar los bienes reales, no siempre los últimos inventarios, copias elaboradas sobre los múltiples cargos y datas redactados previamente, son siempre las fuentes de información más precisas. Por la importancia de publicar por vez primera el inventario completo de éstos, nos permitimos cansar al lector con su lista detallada.

Libros de su mag. [Carlos V] que estaban en vn cofre (Simancas).

- Vn libro de mano de pergamino que trata de la caça que el primer erenglon dize qui comiença y el postrero dize si con me yl mens vervet. El qual esta enquadernado en tablas coloradas labradas de oro con quatro manezillas de laton.

- La quarta parte del bita christi cartuxano cubierto de quero colorado sobre tabla y escrito en rromance.

- Otro libro en pergamino escrito de mano con dos manos de plata dorado que comiença tablas de las fiestas y acaba a folio nobenta.

- Otro libro ni mas ni menos que el sobredicho con sus manos de plata dorada que comiença tablas de las fiestas y acaba trubricam supra dictam, tambien de mano en pergamino scripto.

- Otro libro de pergamino de mano que no esta enquadernado que tiene setenta y çinco quadernos. El primero dellos comiença annos habet menses, y en el postrero comiença done ponas. El qual es brebiario.

i6 LAFUENTE, Modesto y SANCHEZ LORO, Domingo: entre los españoles, se ocuparon del Inventario, publicándolo, respectivamente, en sus obras Historia General de España, apéndice 8 del tomo 12, y en la Inquiesud postrimera de Carlos V (Cáceres, 1957-1958), tomo II. Más recientemente lo han estudiado MORÁN, Miguel y CHECA CREMADES, Fernando: El colecrionismo en España, Madrid, ediciones Cácedra, 1985, pp. 41-61; Almudena PÉrEZ DE TUDELA, «El reziro del Emperador Carlos V en el Monasterio de Yuste», en Monjes y Monasterios Españoles. Bibliotecas, Arcbivos y Escritorios..., (Madrid, Ediciones Escurialenses, 1995), I, pp. 1287-1301; GarCíA SIMÓN, Agustín: El ocaso del Emperador. Carlos $V$ en Yuste, Madrid, Editorial Nerea, 1995, pp. 73-82; y recientemente CHECA CREMADes de nuevo, Carlos V. La imagen del poder en el Renacimiento, Madrid, Ediciones El Viso, 1999, pp. 311-312.

17 BEER, Rudolf: "Acten, regesten und inventare ausdem Archivo General zu Simancas", Jabrbuch der Kunshistorischen Sammlungen des Allerböchsten Kaiserbauses, 12 (1891), p. CLXXIII.

is MORÁN CHECA, El coleccionismo en España, op. cit., p. 53, n. 25. 
- Otro libro cubierto de quero que comiença Eludaçio Salmorum in omnes salmos y acaba en el postrer rrenglon ysot nun et vsquem Eterna secula. El qual esta enquadernado en tablas y ençima bezerro.

- Otro libro de mano escrito en papel en castellano que es rrelox de prinçipes que comiença en la primera plana deziendo comiença el prologo dirijido y comiença la postrera plana por que yo a mis hijos. El qual tiene vnas çerraduras de plata con vnas ymagenes en ellas.

- Otro libro en español de mano que se llama marco aurelio escrito en papel, que co* miença en la rerçera hoja haga cuenta que no pierde nada y feneçe en la postrera, muy desconsolado.

- Otro libro de mano escrito en papel y en castellano que comiença en la primera hoja, comiença el prologo en el libro llamado las dibisas de guebara y acaba en el postrero trenglon: todos commo si a todos se los obiera muerto aquel dia que sus hijos. El qual esta enquadernado en tablas y quero ençima de pie de moro.

- Otro libro de mano en pergamino escrito en ytaliano de la bida de los Emperadores, que comiença en la primera hoja, Julio çesar, y acaba en lo alto de la prostrimera hoja, començando teodosio. El qual esta enquadernado en tablas de papel negras, ençima yestacadas de oro em partes.

- Otro libro de mano escrito en papel en françes llamado bejeçio de re militare y comiença en la primera hoja, sensuit, y en la postrera comiença tur siourss. El qual esta enquadernado en tablas de papel, cubierto de negro.

- Otro libro de mano françes cubierto de pergamino y escrito en papel que comiença en la segunda hoja, en ayne, y acaba, benoit saint spiritu.

- Otro libro de mano escrito en papel en françes començando en la primera hoja, mill y quatroçientos y nobenta y dos, y acaba en la postrera, granada.

- Otro libro cubierto de tafetan colorado escrito de mano en papel, en latin, començando, ad catulum, y acaba, sepulcrum.

- Otro libro cubierto de tafetan berde escrito en español y en pergamino començando, al muy alto Emperador, y a la postrera hoja, comiença para el onbre.

- Otro libro en lengua ytaliana, de molde començando, de Caio Julio çesar, cubierto de quero colorado.

- Otro libro de mano escrito en pergamino y cubierto de pergamino blanco en ytaliano, començando, qui comença y acaba alberto de Alemaña.

- Otro libro cubierto de terçiopelo carmesi de molde en latin que comiença piperonis y acaba, en la penultima hoja, inconspetu alti siui mente.

- Otro libro ymprimido en françes començando, l'arbre des batailles, y acaba en la penultima hoja, bien est serui et tente amne. El qual esta cubierto de quero azul dotado.

- Otro libro grande de mano escrito en pergamino en lengua françes que se dize las cronicas de francia. El qual esta cubierto de quero blanco con çinco tachones de cobre en cada tabla.

- Vn libro escrito en pergamino ymprimido en lengua tudesca yluminada en muchas partes, el qual esta cubierto de quero negro sobre tabla.

- Otro libro grande escrito de mano en pergamino, en françes, que se dize las rubricas de orosio, el qual esta cubierto de tabla y de quero blanco y seis tachones de laton.

- Otro libro de mano escrito en pergamino y en latin, que comiença liber trium oficiorum, el qual esta cubierto de tablas de papel coloradas y se ata con çintas.

- Otro libro pequeño escrito en pergamino y en françes que se dize joan jerman que tiene en la primera hoja vna nao de vn mastil yluminada. 
- Otro libro en papel escrito de mano que se dize, el libro de nobleza, el qual esta escrito en françes en pocas hojas y tiene al cabo vnos escudos chiquitos en vna plana del.

- Otro libro de papel ymprimido en español que trata de la decendençia de los reyes de aragon enquadernado en pie de moro y no tiene manezuelas.

- Otro libro ymprimido en latin tratando de la decendençia de los reyes de aragon que se llama lucio matino enquadernado en tablas de papel de pie de moro.

- Otro libro roto y desenquadernado escrito en papel y en françes, en coplas.

- Otro libro en pergamino, en latin, ynprimido que trata de vna quistion de teologia que se llama alfonsina.

- Otro libro grande de mano en papel en lengua española que se dize catalogo de los rreyes de castilla escrito el titulo de colorado, cubierto de tabla y negro.

- Otro libro cubierto de terçiopelo morado escrito en pergamino de mano en ytaliano que comiença qiu comintia ... y acaba grabe y tenpesta.

- Diez y muchos papeles de pinturas dibersas de sitios de lugares, vnos en pergamino y otros en papel, ay algunos en tela.

- Va pergamino de las armas y nombres de los caballeros de la horden de la Jarretierra de ynglaterra.

Toda esta "partida» de libros fue entregada a Gil Sánchez de Bazán, criado de Felipe II. Pero el inventario de Simancas es prolífico en recovecos donde se ocultaron diversos libros y papeles. Así, Rudolf Beer recoge cierta «caxa blanca, en que está dentro unos pattones de la puente, que Jullio Çesar hizo sobre un rio" ${ }^{29}$. Más adelante (y dejamos aparte los libros y cartas de marear), se incluyen entre las cosas en poder de María Escolastres, que no estaban asentadas en el inventario: «Un libro grande, escrito de mano en pergamino, en Françes, yluminado, que se llama Los comentarios de Julio Çesar y Ponpeyo, que tiene ystorias, que esta cubierto de colorado sobre tabla y en cada tabla quatro cantoneras de laton con sus bollones, que las clavan, y en el medio un bollon en cruz y unos correones con sus hevillas», y "Otras oras de Nuestra Señora de ochava de pliego doradas; no tienen manezuelas ni çintas; estan enquadernadas en quero colorado dorado" ${ }^{20}$. Asimismo, en un cofre, en poder de Diego Jordan, teniente del alcalde de Simancas, aparecieron, junto con unos relojes, cuatro libros de a folio y pergamino, encuadernados en cuero negro y con las armas imperiales en las tapas, titulados «Ephemerides», «Longitudo terre», «la tabla de los edises (sic., por eclises), y «El canone», éste con un retrato del emperador ${ }^{21}$. Estos libros fueron entregados por Felipe al Escorial, con la indicación de que los había compuesto Pedro Apiano para el manejo de otros tres

\footnotetext{
19 BEER, «acten, regesten...», op. cis., p. CLXXII. Encre más cosas provenientes de las Indias. Quizá se tratara de un diseño copiado por indios americanos, de los que se admiraba en la época su capacidad para copiar dibujos y lecras de molde.

20 Ibidem, p. clxxvi.

i) Ibidem, p. cIXXXill.
} 
instrumentos matemáticos que iban con los citados volúmenes ${ }^{22}$. Sobre los libros de astronomía y naútica de Carlos $\mathrm{V}$ remitimos a un interesante estudio de Mariano Esteban Piñeiro y otros 23 .

Para completar el contenido de la biblioteca postrimera del emperador, añadimos la lista, ya conocida, de los libros que tenía en el monasterio de Yuste:

«Vn libro del cavallero determinado en lengua françesa cubierto de terciopelo carmesi luminadas las ymagenes que en el avia.

Otro libro yntitulado boecio de consolaçion en pergamino escrito de mano en lengua françesa cubierto de terciopelo carmesi.

Otro libro grande yntitulado astronomicum caesaris de $\mathrm{P}^{\mathrm{O}}$ Apiano cubierto de terçiopelo negro con çinco chapas de plata doradas.

Otro libro yntitulado tolomeo con cubiertas de cuero colorado.

Otro libro de rromance de mano del cavallero determinado que traduxo don hernando de acuña con sus figuras yluminados, cubierto de cuero colorado y blanco.

Otros dos libros en frances de molde de la meditaçion cubiertos de cuero de vn tamaño guarneçidos de vna manera.

Otros dos libros de la esposicion de titelman sobre los salmos cubiertos de cuero.

Otro libro de titelman yntitulado suma misterionum christiani fidey.

Otros dos libros yntitulados boeçios en forma mediana de molde, el vno en lengua ytaliana y el otro en español cubiertos de cuero.

Otro libro de mano que hizo santacruz sobre el astronomico çesareo cubierto de cuero leonado.

Otro libro de la guerra de alemaña que hizo el comendador mayor.

Otro libro grande de pargamino con muchos debuxos y patrones de diferentes cosas.

Otro libro que se yntitula la dotrina christiana de constantino.

Otro libro que se yntitula meditaçion de frai Luis de granada.

Los comentarios de çesar en lengua ytaliana cubierto de pergamino.

Otro libro que hecho de mano por frai tomas puerto carrero sobre el salmo de yn te domine speravi.

Otro libro de la dotrina christiana de frai pedro de soto.

Dos breuiarios, el vno de san geronimo y el otro del tromano $n u^{\circ}$ y va ofiçiolo de la semana sançta cubierto de cuero azul dorado, dentro los dichos libros de vn saco de sayeta negra.

Vn misal pequeño antiguo con cubiertas de cuero y maneçilla de oro, con su saco de sayeta

Vnas oras de pergamino de mano, luminadas las figutas, cubiertas de cueto, con las manillas de oro.

22 ZarCo Cuevas Julián: Inventario de las alhajas, pinturas y otras objetos de valor y curiosidad donados por el rey Felipe II al Monasterio de El Escarial. (1571-1598). Madrid, 1930, pp. 216-217. Publicado también en Boletín de la Real Academia de la Historia, 96 (1930), pp. 545-668, y 97 (1930), pp. 34-144.

23 Veáse a este respecto el interesante artículo de EsTeban PIN̂EIRO, Mariano, ViceNTE MAROTO, Isabel y GómEz CREspo, Félix «La recuperación del gran tratado científico de Alonso de Santa Cruz: El Astronómico Real», Asclepio. Revista de Historia de la Medicina $y$ de la Ciencia, XIIV (1992), pp. 3-30. 

plata.

Vn librito de las meditaçiones de san augustin cubierto de cuero, con las manyllas de

Dos libritos pequeños < que> son salterios con las maneçillas de plata, el vno y el otro de hierro.

Otro librito yntitulado precaçiones bibliçe santorum ynpreso en leon año de XLV con cubiertas de cuero y sus manillas.

Otro librito de memorias con sus manillas y pluma de escreuir de oro.

Vn libro escripto de mano de los estatutos de la horden del tuson, cubierto de terçiopelo carmesi y las manillas de plata doradas.

Dos librillos de deboçiones de mano, con cubiertas de cuero negro y las manillas y plumas de oro.

Dos misales, el vno cubierto de terciopelo carmesi y el otro no.

Vn libro de pargamino scripto de mano yluminado y estoriado començando la tabla de los oficios en que esta el offiçio de la natiuidad y a la postre rrequien cantinpace. El qual esta cubierto de cuero leonado con dos manezilas de plata dorada en que estan las armas de S. M., Leon Castilla.

Otro libro scripto de mano luminado y estoriado, al prinçipio del qual esta puesto yn nomine domini: amen, y al fin del ad completorium sicuntur sicut in prima die pasca, el qual esta cubierto de cuero leonado con las manezilas de oro esmaltado de negro por de dentro, y por ençirna vnas rrosas rrelebadas por ençima sin esmaltar.

Dos libros de efemerides pasados, el vno hecho el año de XXXIII y el otro el de XIVIII

Otros dos libros grandes de papel en que estan pintados diferentes arboles e yeruas, hombres e otras cosas de las yndias, scripto en algunas cosas en latin cubiertos de terciopelo carmesi.

Otro libro menor de papel escrito en algunas partes de mano y pintadas diferentes yeruas cubierto de cuero blanco y rroxo dorado.

Çiertos cuadernos de florian do canpo y otros sobre las historias que estauan enbueitos en va paño».

\section{$\mathrm{Y}$ aparte se cita:}

«Una bolsa de terciopelo negro y en ella un librillo de oro esmaltado de negro, que tiene cinco hojas con las dos cubiertas, y son de oro, con el retrato del rey de Francia y su genealogía. Y en la misma bolsita está el retrato del emperador, cuando era mozo, engastado en orom.

Añadimos también a esta lista, la aneja, publicada por Hueso Rolland, de los «Libros que no debían venderse de los bienes de Yuste»:

*Un librillo de oro con retratos.

Un librillo de oro, con tres quadrantes, dos de uno y uno de plata.

Dos brebiarios romano y de Sant Jeronimo y un oficio de la semana santa.

Un misal pequeño.

Unas horas iluminadas.

Dos salterios pequeños.

Un libro de memoria de oro.

Un libro de mano de la dicha orden (Del toison). 
Dos libros de devociones de mano.

Una carta de marear como libro que dio el Principe Doria.

Otra de la discrepancia de España.

Dos enboltorios de cartas de pergamino.

Quatro pinturas de fortificaciones.

Una scriptura de las tablas de dimension.

Un libro de pergamino de mano iluminado de la misa.

Otro iluminado de mano istoriado." (AGS. Descargos de Carlos V. Leg. 13, folio 342).

Al leer las descripciones de los libros que hace este inventario es comprensible que no se haya identificado gran parte de su contenido. Aunque hay obras y autores claramente reconocibles, se trata de una minoría (Apiano, Santa Cruz, Marche), y sobre ellos los biógrafos del César han vuelto una y otra vez, creando, quizá, una imagen distorsionada de las lecturas carolinas en Yuste, distorsionada - decimos - por incompleta. Sin duda, una de las principales dificultades que nos encontramos al tratar de identificar algunos títulos, es la escrupulosa desconfianza que exhibió el oficial real en Simancas a la hora de realizar su trabajo. Como vemos, de muchos ejemplares oculta el título, no por pérdida del mismo, y prefiere señalar con qué palabras empieza o termina la obra en cuestión, ya sea impresa o manuscrita, y ien el colmo del prurito!, en otros no refiere la última frase, sino las primeras palabras de la penúltima hoja, como si temiera que alguien, advertido de esta práctica notarial, tratara de hurtar el libro, con la precaución de arrancar o sustituir para su provecho esa última hoja. Quizá actuara movido por la desconfianza de que hubiera cofres con bienes del soberano fuera del castillo, en poder, como hemos visto, de María Escolastres y del teniente Jordan. Pero en Yuste los criados reales tampoco fueron más diligentes. Quizá porque la cantidad de volúmenes era escasa, "olvidaron» indicar títulos, o referir si se trataba de obras impresas o manuscritas, aumentando la confusión.

Se hace necesario, pues, la consulta de otras fuentes complementarias que permitan seguir la historia de estos libros. Por suerte, Felipe II decidió reservarse la mayor parte de éstos, haciendo uso de una cláusula del testamento de su padre $^{24}$ (sólo tres se vendieron en almoneda), y, en consecuencia, la biblioteca de Carlos V se integró, primero, en la librería del Real Alcázar, y después en la de la Real Biblioteca de El Escorial, donde fueton destinados en última instancia la mayor parte de los ejemplares arriba enumerados. Entre estas fuentes, debemos referirnos en primer lugar a los diversos inventarios escurialenses, que se remontan a las listas de libros entregados entre 1565 y 1568, publicadas por Guillermo Antolín ${ }^{25}$, les siguen el inventario de manuscritos de 1572, el catá-

24 Testamento de Carlos $\boldsymbol{V}$. Edición facsímil. Introducción de Manuel Fernández Álvarez, Madrid, Editora Nacional, 1982, Colección Documenta, p. 9.

25 ANTOLiN, Guillermo: "La Librería de Felipe I (Datos para su reconscizución)», La Ciudad de Dios, CXVIII (1919). 
logo de los libros a cargo de Serojas (1574) ${ }^{26}$, los inventarios de libros prohibidos y de otros títulos hallados en palacio entre 1574 y 1576 , el conocido Inventario o Catálogo de 1576, y el inventario general de las entregas hechas por el Rey al Monasterio entre 1571 y 1598 , publicados por Zarco, en cita anterior.

Aunando ambas fuentes, los inventarios de los bienes de Carlos $\mathrm{V}$ y los de la biblioteca de Felipe II, nos ha sido posible identificar y seguir el rastro de una serie de volúmenes que, de otra manera, sería imposible reconocer. Hemos de advertir, no obstante, que algunas de las identificaciones que hacemos se basan en suposiciones, pues se refieren a obras que desaparecieron en El Escorial, sobre todo manuscritos, devorados por las llamas en el incendio de 1671 . Los códices en francés y en italiano fueton los más afectados, y es muy poco lo que ya hoy se conserva. Otras referencias se tornan muy esquivas, como aquel libro «en cuarto, escrito de mano que parece se envió al emperador en Flandes antes que partiese para España», en poder de Felipe II en $1598^{27}$. Más suerte ha habido con los impresos y con manuscritos en otras lenguas, castellana, latina e italiana. De esta manera, ha sido posible obtener un "retrato" fiel de aquella librería cesárea en España. Entre los libros del César Carlos pueden advertirse dos grandes grupos de obras. Por una lado aquellas que tenían para el emperador un significado patrimonial regio o político, y por otro lado, aquellas que eran de su uso más personal. Los primeros se guardaron en el castillo de Simancas, en un cofre adjunto al que contenía la biblioteca de la reina doña Juana; los segundos acompañaron a Carlos V hasta Yuste.

En el primer conjunto de obras, destaca la selecta colección de códices, iluminados y ricamente encuadernados, escritos en lengua francesa, que Carlos había recibido en calidad de heredero de los Duques de Borgoña ${ }^{28}$. Para él, estas obras poséan un valor simbólico y sentimental muy grande, pues la cuestión borgoñona había sido esencial en su política y en su propia visión personal. Precisamente uno de los manuscritos, en pergamino y francés, «que se dize joan jerman», era un tratado sobre la conservación de la casa de Borgoña, escrito por Jean Germain (1400-1461), primer canciller de la orden del Toisón ${ }^{29}$. Destaca asimismo el volumen de las citadas Crónicas de Francia, probablemente

26 Catalogo de los Libros de Su Majestad a cargo de Serojas., RBME, Ms. \&-II-15, ff. 283r-314v.

27 ANDRÉs, Gregorio de: «Los libros de la testamentaría de Felipe II (1611)», en Documentos pana La Historia del Monasterio de San Lorenzo el Real de El Escorial, Madrid, Imprenta del Monasterio, 1964. VII, p. $401, \mathrm{n}^{0} 89$.

29 CLAvería, Carlos: «En torno a la intimidad y el borgoñismo de Carlos V», Cuadernos Hispanoamericanos, 113 (1958), pp. 93-117.

29 eb 1 Juan German de la conseruacion de la casa de Borgoña en pergamino de mano illuminadow, entre los libros de filosofia en francés y en $4^{\circ}$ a cargo de Serojas. (RBME, ms.\&-II-15, folio 299v). Inventario de 1576: "De la casa de Borgoña, cómo se ha de conservar "por Juan Germain" " (IV-O-I), entre los manuscritos de leyes en francés y en $4^{\circ}$. Gregorio de ANDRÉs, «Entrega de la librería real de Felipe II (1576)", en Documentos para la Historia del Monasterio de San Lorenzo el Real de El Escorial, Madrid, Imprenta del Monasterio, 1964. VII, p. $200, \mathrm{n}^{\circ} 3468$. 
de Monstrelet. Del aprecio de Carlos por la lectura de esta historia nos da idea el hecho de que ya figurara en el inventario de su cámara en 1517. La misma obra que entretuvo su ocio durante la primera de sus travesías a España, le acompañó en la última. Pero, en un monarca tan aficionado a la caza y a la guerra como Carlos $\mathrm{V}$, algunos de estos libros habían tenido algo más que una función de representación dinástica. Es el caso del citado «libro de la caça", sin duda el famoso de Gastón de Foix, como se indica en un inventario filipino de 1574: «Libro de caça en pergamino de mano illuminado del conde Phebo de foix", en francés y folio ${ }^{30}$; o del De re militari, de Vegecio, vademecum imprescindible en la biblioteca de cualquier caudillo renacentista, al igual que los $\mathrm{C}_{0}-$ mentarios de Julio César en francés, e incluso del citado «libro de nobleza», probablemente el que después encontramos en poder de Felipe II como "Tratactado de nobleza y gentileza por Diego de Valera, de mano enquadernado en pergamino", en folio ${ }^{31}$. Desgraciadamente, y como decíamos antes, estos códices en lengua francesa se perdieron en el incendio que asoló la biblioceca manuscrita de El Escorial en 1671.

Mejor suerte tuvo otro libro en francés, que (al estar impreso), se salvó de las llamas. Nos referimos al citado "larbre des batailles", que se corresponde con el Arbre des batailles, de Honoré de Bonnor ${ }^{32}$. Carlos V tenía un ejemplar de la edición parisina de 1527, hoy conservado en la Laurentina. Esta obra contenía, en su pequeño formato, una serie de historias de hechos de armas extraídos de los autores clásicos en materia militar, en especial Vegecio. Encuadernado en cuero con hierros dorados, los folios todavía conservan las marcas de desgaste propios de una lectura prolongada. No resulta difícil imaginar al César releyendo una y otra vez este librito, ya en sus viajes, ya en palacio, o como lectura en campaña, frente a escenas bélicas como la que ilustra una xilografía al principio del mismo. Sin embargo, una vez retirado de los asuntos de gobierno, esta vieja lectura, compañera de batallas, no viajó con su dueño hasta Yuste, al igual que el Vegecio manuscrito antes citado.

Este abandono tiene su sentido sólo en esta etapa final de la vida de Carlos $\mathrm{V}$, cuando los fracasos militares en Innsbruck y Metz le sumen en la depresión. Pero, sin duda, en él siempre había predominado una mentalidad caballeresca (heredada de Carlos el Temerario, duque de Borgoña, pero también de su abuelo, Maximiliano I), y esto no podía dejar de reflejarse en sus lecturas. Así,

\footnotetext{
30 RBME, ms. \&-II.15, fol. 301r.

31 Ibidem, fol. 302v.

32 Honóre de BONNOR, L Arbre des ba tailles Et fleur de cbevalerie selon Vegece, awecques plusieur,s bystoires eft\} villes nemo\{n\}stra\{n\}ces du fait de guerre par luy ex sraictes $d(e)$ Frontin, Valere e\{t\} de plusieurs sautitres aucteurs, co $\{m\}$ me ponrrez veoir cy apres. On les vend a Paris en la grant rue sainct Jaques a lenseigne de la Roze blanche couro\{n\}nee par Phelippe le Noir, Patís, Philippe le Noir, 1527, 80. RBME, 100-IV-24. La penultima hoja, en el verso, concluye: «Qui est large chascun le prise Bien est seruy et tant ame», como se indica en el inventario. Encuadernación renacentista flamenca en cuero verde (no azul) y papelón, dorada.
} 
el libro en alemán que se guardó en Simancas era, en realidad, un ejemplar del Theuerdank, la segunda de parte de la magna obra biográfica que Maximiliano concibió, en contacto con la épica caballeresca de finales de la Edad Media. En este libro, bien descrito en el inventario (aunque parezca contradictorio, como «escrito en pergamino ymprimido en lengua tudesca yluminada en muchas partes", pues se trata de una obra impresa sobre pergamino y con las xilografías bellamente iluminadas), Maximiliano natró a su secretario Treitzsauerwein los riesgos y aventuras que corrió en el viaje al encuentro en de su prometida, María de Borgoña. La presencia de esta obra en la biblioteca de Carlos V tiene una lectura inevitable. Se trata del modelo que siguió para la composición de sus propias memorias, que dictó, al igual que Maximiliano, a uno de sus criados, en este caso Guillaume van Male, en 1550. Como antes hiciera su abuelo, Carlos se había propuesto realizar su propia biografía. Aunque esta decisión suele vincularse con un cierto deseo de imitar a Julio César, lo cierto es que el Theuerdank, presente en su biblioteca, como las otras dos partes de esta epopeya biográfíca (el Freydal y el Weisskuning) se presentan como un modelo dinástico más cercano. Sobre este punto volveremos más adelante, ya que el Theuerdank debe vincularse con otros dos libros que Carlos V tuvo en Yuste, El Caballero determinado, en francés y castellano.

En segundo lugar, también encontramos en la biblioteca de Carlos $\mathrm{V}$ una selecta colección de libros litúrgicos, entre ellos los volúmenes del famoso Breviarium, o vesperal-misal, que lleva su nombre, que son descritos bajo el título "tabla de las fiestas" y «el qual es brebiario». Estos magníficos códices, cubiertos con encuadernaciones mudéjares, y conservados en la Laurentina ${ }^{33}$, fueron realizados en España, se cree que en Toledo, por un grupo de iluminadores y calígrafos castellanos, entre los que se ha creido identificar a Bernardino de Canderroa, Diego de Arroyo y Francisco de Buitrago ${ }^{34}$, pero que parece obra de Correa de Vivar ${ }^{35}$. También se encontraba en Simancas el no menos conocido Officium Salomonis («otro libro de mano escrito en pergamino y en latin, que comiença liber trium oficiorum«), que el impresor Robert de Kayser ofreció al

33 Breviarikm Caroli V. RBME, Virrinas 4, 5, 6 y 7 .

${ }_{34}$ JANINI, José: Manuscritor litúrgicos de las bibliotecas de España. I. Castilla y Navarra, Burgos, 1977, p. 109; MunTadA, Anna: Misal Rico de Cisneras, Madrid, 1992, pp. 80 y 116-117; DomínGUEZ BorDONA, Jesús: Expatición de códices miniados españoles: catálogo, Madrid, Sociedad Española de Amigos del Arte, 1929, pp. 165-166.

35 Isabel Mateo Gómez sostiene por razones estilísticas que el Breviario fue realizado por un pintor toledano, Juan Correa de Vivar (c. 1500-1566), discípulo de Juan de Borgoña. Correa trabajó para la nobleza toledano y los arzobispos de la ciudad. Para el cardenal Fonseca iluminó el Misal de Fonseca, en la catedral de Toledo, y éste prelado le encomendó la ejecución de este Breviario hacia 1525. En el vitr. 5 aparecen Carlos $V$ como un dios acompañado de Fonseca (folio II). Y debió terminarlo hacia 1540 , con la ayuda de un discípulo. I. Mateo Gómez ha hallado grandes semejanzas entre escenas del Breviario y retablos pintados por el artista toledano en iglesias madrileñas y manchegas. (Vid. MATEO GÓMEZ, Isabel: Juan Correa de Vivar, Madrid, 1983; y «Nuevas obras de Juan Correa de Vivar y su círculo", Academia, (1994), pp. 293-313).

Hispania, LX/3, núm. 206 (2000) 911-944 
nuevo emperador, en Gante, en $1520^{36}$. El hecho de que Carlos V no se sirviera de ellos en Yuste, nos da cuenta de su carácter de joyas bibliográficas, como las de los otros manuscritos que les acompañaban. Eran «tesoros», como la plata, o las joyas «ancianas» de Borgoña, y en Simancas permanecieron. Las cotidianas devociones litúrgicas del César se vertieron sobre otro grupo, menos ampuloso, de misales, horas y breviarios, que encontramos entre sus libros de Yuste.

En tercer lugar aparece entre sus libros, y esto sí constituye una sorpresa, un grupo de manuscritos en italiano. La mayor parte de éstos, como ocurrió con los escritos en lengua francesa, han desaparecido, pero creemos que, en su mayor parte, provenían de la antigua y afamada biblioteca napolitana de Alfonso $\mathrm{V}$ de Aragón. Estos códices, en los que en algunos -como la Historia Natural de Plinio - se iluminó un escudo a plana entera del propio emperador $^{37}$, parece que llegaron a su poder por medio del Duque de Calabria, heredeto de parte de aquella magnífica biblioteca. Virrey de Valencia, y padrino en la boda de Carlos con Isabel de Aviz, en 1526, no ha de sorprender que hiciera a su señor este obsequio. En 1542 también obsequió al príncipe Felipe, en Valencia, con otro grupo de ricos códices de su biblioteca, de temática histórico y escolar ${ }^{38}$. Para Carlos V, en cambio, el Duque se inclinó por obras de filosofia natural, geografía e historia cesárea, temas que suscitaban con gran fuerza la curiosidad del monarca. Se citan así, una Vida de emperadores, hoy perdida, pero que parece corresponderse con el manuscrito catalogado en 1574 y en 1576 como «Las vidas de los emperadores desde Julio César hasta Valentiniano",

36 Robert de KEYSER; LIBER TRIVM OFFICI-ORVM EX SOLOMONE COLLECTVS ET EX ALIIS LOCIS SACRIS. Matufine, Vespere et Completorium ex uita Solomonis secundum usum Illustriss (imi) atque excelentiss (imi) Regi Caroli ex Hispania sua redeuntis et profiscentis in Germaniam ad lmperii susceptionem. Códice en vitela, $37 \mathrm{ff}$., $270 \times 180 \mathrm{~mm}$. Latín. Nurnerosas miniaturas, iniciales y capitales en oro y colores, muchas de las cuales son heráldicas. RBME, Vitrina 13. Encuadernación tenacentista en cuero rojo y papelón, dorada, aunque ha perdido gran parte de las estampaciones en este metal. En el centro cinco águilas tricéfalas, con la cabeza central coronada. Sobre este códice vid. VAN DER GHEYN, J.: Un manuscrit de limprimeur gantois Robert de Keyser a la bibliotheque de lEscurial, Gante, 1907; y DOMj́NGUEZ RODRígueZ, Ana: «El Officium Salomonis de Carlos V en el Monasterio de El Escorial. Alfonso X y el planeta Sol. Absolutismo monárquico y hermetismon, Reales Sitios, XXII (1985), n $\mathrm{n}^{\circ}$ 83, pp. 11-28. Un renovado estudio de este códice por CHECA Cremades, Fernando: Carlos V. La imagen del poder en el Renacimiento, Madrid, ediciones El Viso, 1999.

37 Cayo PLINIO SEGUNDO, QVI COMINCIA LO PROLAGO DI PLINIO NOVOCOMENSE DELLORDINE DE CAVALIERI SOPRA LO LIBRO DELLA HISTORLA NATVRALE. Códice sobre pergamino en folio ( $415 \times 270 \mathrm{~mm}$ ), $307 \mathrm{ff}$. +2 no numerados al principio, en cifras arábigas. Lerra del siglo XV. Iniciales miniadas en oro y colores. Los títulos en rojo y los epígrafes en oro y azul, alternando las líneas. Dedicado al rey Ferrante de Napoles. En el folio $28 \mathrm{v}$ un escudo iluminado de Carlos V, que ocupa por completo la plana, posterior a la confección del manuscrito, soscenido por águila bicéfala. En el folio siguienre (29r), al pie, también se iluminó este mismo blasón de Austria, con águila bicéfala, sostenido por putti de la ilurninación original. RBME, h-I-3. Concluye en el folio 307v: $\propto$ Et euasi doue si mettono le uiuande riposti fanno sudore el quale annuntia graue tempestan, como se indica en el inventario. Encuadernación entelada en papelón y terciopelo morado.

38 GoNZALO, La aLibreria ricas de Felipe II, op. cit., $\pi^{\circ} 359,555,835$ y 859. 
indicándose que "fue este libro del Rey Don Alonso de Napoles»39, u otro códice que empezaba "qui comiença», y en la última hoja empezaba "Alberto de Alemaña», de difícil identificación, pero que quizá fuera cierto "Libro de monteria del conde Phoebus illuminado", en toscano y folio, que figura junto con los dos anteriores en poder de Felipe II, y la advertencia de que eran del rey Alfonso ${ }^{40}$.

Que el emperador quisiera llevar consigo estos libros italianos a España no debe interpretarse sólo como una cuestión de gusto personal, sino también como una decisión tanto bibliófila como dinástica. No en vano, junto con aquellos también tenía una traducción de latín al castellano, manuscrita, de los famosos Dichos y bechos del rey Alfonso V, de Antonio Becadelli, el Panormitano, realizada por su consejero Fortún de Ercilla. El códice, citado de manera escueta en el inventario de los bienes del César en Yuste («otro libro cubierto de tafetan berde escrito en español y en pergamino començando al muy alto Emperador"), se corresponde sin duda alguna con el manuscrito Los dichos y bechos del Rey don alonso que quedaron en memoria de algunos, y que conserva en El Escorial con la firma autógrafa de su traductor y la cubierta en tela verde ${ }^{4 l}$. La dedicatoria al César es significativa del papel que en su hispanización tuvo la figura de Alfonso V de Nápoles:

"Yo deseaua auer toda la historia del rey alfonso, porque eran tan sabio tan justo y tan bueno que qualquier cosa que hiziese, le salia absolutamente perfecta: y todo era digno de ser a todos exemplo. La qual los embaxadores de veneçia lleuaron de napoles comprada por muy preçiosa y no la queriendo comunicar, como cosa de gran tesoro, la quisieran presentar al rey catholico vuestro abuelo: mas en breue suma de sus dichos y hechos esta aquí escripta, e yo con mi grueso pinzel la traduxe y con mi pobre y ocupado ingenio la escreui en lengua castellana, y en mi deseo de seruiros ni en mis alhajas no tuue por çierto cosa mas preçiosa por agora para vuestro retraimiento, que la medalla del rey alfonso que por ser

39 «a 1202 . Vidas de los emperadores en pergamino <de mano> fue este libro del Rey Don Alonso de Napoles", entre los libros de historia en coscano y en folio. Catálogo de los libros de S. $M$. que se ballaron en poder de Serojas en 1574, RBME, ms. \&-II.15, fol. 295v. Y que dos años más tarde se describe ya en El Escorial como una Vida de emperadores desde Julio César basta Valentiniano, en tocano y folio. (ANDRÉS, «Enerega de la librería real de Felipe II», op. cit., p. 197, n $^{0} 3429$ ).

40 RBME, ms. \&-II-15, fol. 324v. Parece correponderse con otro anterior, a cargo de Serojas, «Historia de animales y Arte de caça en peragmino de mano illuminado con cubierta de brocado, de la librería del Rey Don Alfonso de Napoles", en toscano y folio (ibidem, fol. 295r), si bien la encudernación no es de pergamino, como el de Carlos V. En el inventario de 1576 se cataloga como "Libto de animales y arte de caza por Juan Gastón con pinturas", (ANDRés, Entrega de la librería real de Felipe II", op. cit., p. 196, n ${ }^{\circ} 3415$ ).

41 Fortún García Ercilla y ARTEAGA, Los dichos y becbos del Rey do(n) alo (n\}so q\{ue\} quedaro $n\}$ en memoria de algunos. Códice en vitela, 114 hojas foliadas a tinta con numeración arábiga. RBME, eIV 4 . Encuadernación entelada. Comienza con la dedicatoria al emperador: «Al muy alto emperador don Charlos y rey catholico nro. Señor.» (folio 1r), y el penúltimo folio escrito comienza: «... Para el ho[m]bre: no», tal y como se indica en el inventario de los bienes guardados en Simancas.

Hipania, LX/3, núm. 206 (2000) 911-944 
del que es me esta bien darla a vuestra majestad alegremente reçe / (folio 2v) uirla: que no puede ser que con la figura del diuino animo deste gran pariente a quien suçedistes, el vuestro no sea alegre, y conosca en el su buen parentesco. Dios tenga a vuestra majestad de su mano e le sea tan misericordioso:que en sus hechos sea su nombre ensalçado eternalmente».

(y autógrafo): «De V. S. C. Mat.

sieruo fotuño derçilla».

La biblioteca de Alfonso $\mathrm{V}$ gozaba en la época de una fama extraordinaria, poseer algunos de los volúmenes que la habían integrado era considerado un privilegio. Asimismo, como obras que tenían una procedencia regia, su vinculación con Carlos $\mathrm{V}$ formaba parte de la indispensable continuidad dinástica. Estos códices, pues, como aquellos otros en francés, ligados a los duques de Borgoña, participaban de idéntica mística monárquica. Felipe II sabrá ver esto todavía en mayor medida, y reunirá para la biblioteca del Escorial una magnífica colección de libros procedentes de la biblioteca napolitana de Alfonso V, junto con los libros de Isabel la Católica, que mandará traer de Granada. De esta manera quiso dotar a la biblioteca de El Escorial de un carácter verdaderamente regio, como centro que aglutinara los fondos librarios de la Corona de España, de manera paralela a como en Bruselas, había fundado en 1559 otra biblioteca real, que conservaba los fondos de la corona ducal de Borgoña.

Dentro de esta misma concepción monárquica del libro, pero con una utilidad diferente, Carlos $\mathrm{V}$ dejó en el castillo de Simancas todas aquellas crónicas que, o se referían a los reinos peninsulares, o que había ido recibiendo a lo largo de su reinado. El César tuvo siempre en gran estima los intentos por escribir una crónica general de España, englobara o no su reinado. Los cronistas reales fueron las personas encargadas de desplegar esta tarea. Éstos escribían a cuenta de la Corona, y tenían la obligación de entregar sus papeles al rey, ya en vida, una vez redactados, o tras su muerte, ya que se trataba de un material histórico que se consideraba como propiedad de la Corona. No ha de sorprender, por tanto, que Carlos V no quisiera dejar en Flandes una serie de crónicas, que él había ido recopilando, y que a su muerte esperaba que pudieran servir para continuar la tarea de escribir esa historia general de España. La selección es bastante representativa de la historiograffa castellana de su reinado: Lucio Marineo Sículo, Gonzalo Fernández de Oviedo y Fray Antonio de Guevara (los papeles de Pedro Mexía habían sido reclamados por Felipe en 1551). Por cronología, es de suponer que las obras historiográficas de Sículo fueron las primeras en llegar a la biblioteca carolina. En el inventario de Yuste se citan dos genealogías de los reyes de Aragón, una en latín y otra en castellano, que sólo pueden corresponderse con su Pandit Aragoniae veterum primordia regum, (Zaragoza, 1509), y con su edición castellana, Cronica daragon (Valencia, 1524). Su localización actual resulta compleja, pues ambas obras se adquirieron también 
para el entonces príncipe Felipe, en 1544 y $1547^{42}$, confundiéndose los ejemplares en la Laurentina.

Con menos dudas se puede datar la entrega a Carlos del Catálogo Real de Castilla, de Gonzalo Fernández de Oviedo, pues él mismo cuenta en el proemio que hizo entrega del original, manuscrito e ilustrado, a la emperatriz, en 1532, en ausencia del soberano, a quien lo dedicaba:

«... y puesto no soy digno de bessar vuestros reales pies con mi ofrenda ofrezcola a vuestra misma Cesarea mag. en las reales manos de la muy poderosa e bienauenturada Emperatriz doña Ysabel vuestra consorte: Quia estis duo in came vna, para que de más de mandar que tan dignas historias se conseruen y biuan, aprenda a leer en ellas el serenissimo prinçipe don Phelipe, en quien vuestros señorios e monarchia esperan suçeder a largos tiempos, porque de más de exerçitarse su pueriçia (quando a tal edad llegue) en cosas tan memorables, sabra desde su niñez acordarsse de su antigua e real prosapia y terna aprendida su memoria muchos actos que los buenos prinçipes sus predeçessores obraron y los que muchos varones illustres e leales subditos suyos han fecho, esclareçidos por sus hazañas» 33 .

Los tres manuscritos de Guevara, su cronista, el Relox de príncipes, el libro de Marco Aurelio, y el Libro de las vidas, fueron llegando a manos del César a medida que su autor los componía. De estos manuscritos, dos se conservan en la Laurentina, el Marco Aurelio $0^{44}$ y las Vidas ${ }^{45}$, pues el primero, el Relox, si bien fue destinado a esta biblioteca, no entró en 1576 , perdiéndose su rastro hasta la actualidad. Fueron estas obras muy apreciadas por Carlos V, a pesar de sus ficciones literarias e historicistas, y señal de su lectura detenida es la cita que de

12 Gonzalo, La «Librería rica», op. cit., pp. 558-559, n'939 y 940.

43 FERnánDez De Oviedo, Gonzalo: Catbalogo real de Castilla y de todos los Reyes de las Españas; y de Napoles y Secilia, e de los reyes y Señores dellas Casas de Francia, Austria, Holanda y Borgoña, RBME. h-I-7, fol. $3 \mathrm{r}$.

44 Guevara, Antonio de: Comienga el prologo dirigido a la S. C. C. M. Del inuictissimo semper Augusto el Emperador nuestro señor don CARLOS <Sexto> quinto de este nombre: por la graçia de dios Rey de Cantilla, de Leon, de Aragon Ec, embiado por Fray Antonio de Gueudra de la orden de los frailes menores de La obseruancia, predicador en la capilla de su imperial Maiestad: sobre la transhasion que bizo de Griego en Latin, de Latin en Romançe al libro llamado Aureo:el qual babla de los tiempor de Marro Aurelio decimo Septimo Empera-dor de Roma. Códice en papel, 167 hs., foliadas a tinta roja con numeración romana y a lápiz. RBME, g- II-14. Encuadernación escurialense. El folio III comienza: «haga cuenta que no pierde nada, mas el que pierde la fama», tal y como se indica en el inventario de Simancas.

is Antonio de Guevara, Comjenca el prologo en el libro llamado las vidas de Guetuara dirigido al soberano señor don Carlos. (V) <sexto> empler\}ador deste nombre: por el maesto don Antonio de guevara obispo de Guadix predicador cbronista y del consejo de su magestad frayle menor de la obseruancia bijo de sant francisco de Valladolid. Códice en papel, 180 hs., mal foliadas a tinta con numeración arábiga, 3 hs., al principio en blanco y orras 3 al final, $290 \times 203 \mathrm{~mm}$. Los ff., 14, 32, 63, 64, I10, 111, 145-147 en blanco. RBME, g-II-18. Encuadernación mudéjar. Al final, en el folio $177 \mathrm{r}$, concluye el texto: «sepultados, como si a rodos se les vbieran muerto aquel dia sus hijos. finis. < de los emperadores $>$ ». Encuadernación mudéjar en cuero color avellana oscuro y papelón, gofrada. 
la primera obra hizo en sus instrucciones secretas a Felipe II, en 1543, cuando le presenta al ayo Juan de Zúñiga, como su «rrelox y despertador» ${ }^{46}$, en clara alusión a la obra de Guevara. La hermana de Carlos V, María de Hungría, también poseyó varias obras del mismo autot, traducidas al francés ${ }^{47}$. En este contexto, la presencia de sus libros en la biblioteca carolina permite relacionar las ideas evasivas y espirituales que Guevara plasmó en su Menosprecio de corte y alabanza de aldea, con las razones del retiro de Carlos en Yuste, y con su "rusticidad»"48.

Por último, en Simancas se guardó un grupo heterogéneo de libros, muchos de molde, y de escaso valor, que creemos representan los restos de aquella biblioteca imperial perdida en Innsbruck, en 1552. Para Carlos V ya no tenían un interés personal, que exigiera su presencia en Yuste, pero al tratarse de libros regalados durante su reinado, consideró que eran tan patrimonio regio como los códices ricos arriba descritos. Sólo así se explica que figuren entre estos un ejemplar de la Alphonsina, de Alfonso Enríquez, abad de Valladolid ${ }^{49}$, otro de la Elucidatio psalmorum, de Frank Tittelmans ${ }^{50}$, y otro del De omni vero oficio, de Giovanni Piperon ${ }^{51}$. El primero, impreso en pergamino, fue probablemente un obsequio de Entíquez, nieto bastardo del Almirante de Castilla, al monarca; el segundo, obra dedicada por Tittelmans a Carlos en 1531, debía tratarse del ejemplar de presentación entregado entonces por el teólogo franciscano; y el tercero, impreso en Nápoles, en 1534, «Regnante CAROLO+V+

46 MARCH, José María: Niñez y juventud de Felipe II. Documentos inéditos sobre sk educación civil, literaria y religiosa y su iniciación al gobierno 1527-1547, Madrid, 1941, II, p. 102. Carlos V a don Felipe. Palamós, 4-may-1543.

17 Vid. Lemaire, «La bibliothèques des imprimés», op. cit., p. 133, n 182 y 183.

48 Checa Cremades, Fernando: Carlos $V$ y la imagen del béroe en el Renacimiento, Madrid, Tau* rus, 1987, p. 61 .

49 Se trata de su examen universitario en reología, celebrado en la universidad de Alcalá de Henares, bajo la dirección del maestro Francisco de Vargas. Alfonso ENRÍQUEZ, Alphonsina acutissimi ac clarissimi illustris iviri domini. d. Alphonsi Enriquez in sacra theologia Baccalasurei. Per doctissimum viru (m) magistrum Franciscum de Vargas: eitusdem Alpbonsinae priorem: correcta. Alcalá de Henares, Arnao Guillén de Brocar, 1523, Fol.- Impreso sobre pergamino. RBME, 59-VI-16. Encuadernación mudéjar en cordobán cobrizo y tablas de madera, gofrada.

so TITtelmans, Frank: ELVCIDATIO in omner Psalmos iuxta veritatem vulgatae et ecclesiae vsitatae aditionis latinat, castigatior quàm vnqua\{m\} anted fuerit,(...), Patís, Jean Savetier para Sebastian Nivell, 1552, Fol. RBME, 59-IX-18. Encuadernación del siglo XIX en pasta, Edición que no tiene porque corresponder con la de Carlos V, si bien esta obra, en otra impresión o no, era la que tenía éste, ya que concluye: eex boc nunc $\mathcal{E}$.... «, al igual que se señala en el inventarió.

51 PIPERo, Giovanni Antonio: Piperonis de omni vero officio libri septem. Omnibvs aeque ac aer ad vitam quo sine spirat nemo ad bene beateqve viven dum necessarii. Autboris iniussu quisquam ne imprimito neute uppiam uendito. Nápoles, Johann Sulzbach de Hagenau, 1534. 4. RBME, 21-V-53. Encuadernación escurialense. Es el de Cartos V, en el folio 205v, la última línea; “... ad dominum qui fecir illum, er in conspectu altissimi mente de precaturn. Encuadernación, parcilla y corce dorado escurialenses. Reencuadernado. La cubierca original entelada se perdió. Inventario de 1574: «a 1 18* Piperon de omni uero officio. Neapoli 1534, con cubierta de terciopelo carmesi», entre los libros de oratoria en latín y en $4^{\circ}$ a cargo de Serojas (RBME, ms. \&-II-15, fol. 286v). 
Imperatore / Augustissimo", fue sin duda un obsequio del autor, aprovechando la llegada a la ciudad del César, triunfante en Túnez un año más tarde. Así lo indica tanto el pie de imprenta como la cubierta original en terciopelo carmesí, habitual en este tipo de regalos.

Es en los libros de Yuste, en cambio, donde se reflejan de manera más níti$\mathrm{da}$ las preocupaciones íntimas de Carlos $\mathrm{V}$ durante su retiro. Si en las obras anteriores todavía estabamos ante al monarca victorioso, señor de dos mundos, en éstos se nos aparece ya el anciano «eremita», dedicado a dos tareas principales: la preparación para la muerte, la liturgia diaria, y el cultivo de dos de sus más acendradas aficiones de gabinete: la astronomía, los relojes y la botánica. No ha de sorprender que la lista se inicie con dos ejemplares del Caballero determinado de Olivier de la Marché, uno en francés, y el otro en castellano, traducido, según se dice en el inventario, por don Hernando de Acuña; o que la lista se complete con tres Boecios, su De consolatione, uno manuscrito en francés, y los otros dos impresos en italiano y castellano, que se conservan en la Laurentina; así como otros dos ejemplares de la exposición latina sobre los salmos de Frank Tittelman, y un volumen de su Misteriorum cbristiani fidei, junto con otros dos «libros en frances de molde la meditaçion», de Robert Ciboule, las doctrinas cristianas del doctor Constantino Ponce de la Fuente y de Pedro de Soto, y, por último, las meditaciones de fray Luis de Granada y las apócrifas de san Agustín.

El universo mental del monarca se nos desvela así de una manera meridiana en la línea de estos tratados, que nos ilustran sobre la preparación para la muerte que el César escogió para sí, lo que se denominaba en los ars moriendi de la época, la «meditación de las postrimerías" ${ }^{32}$. No se trataba de una selección apresurada de lecturas. El Chevalier délibéré, de Olivier de la Marche, formaba parte de su biblioteca desde años atrás, en un manuscrito bellamente iluminado, y que se describe en el inventario. Sobre éste códice debió realizar la traducción al castellano, que después le ayudaron a corregir su secretario, Guillaume van Male, y Hernando de Acuña, su gentilhombre. En 1552 Calvete de Estrella obtuvo de Carlos V la autorización para publicar esta versión del Caballero determinado, si bien salió a nombre de Acuña, pues el César se negó a que su nombre figurara. Sin embargo, no descuido vigilar esta publicación, tanto el texto como las magníficas xilografías que debían ilustrarlo. $Y$ así, Calvete entregó a Carlos V, un ejemplar preparatorio, ilustrado con grabados de Arnold Nicolai d'Anvers, hoy conservado en la Biblioteca Nacional de Madrid ${ }^{53}$, y que

52 Sobre este tema vid. el magnífico estudio de MARTíneZ Gil, Fernando: Muerte y sociedad en la España de los Austrias, Madrid, Siglo XXI, 1993, pp. 66-68.

33 BNM. Mss. 1475. En el inventario de los libros de Carlos V: «otro libro de rromançe de mano del cavallero determinado que traduxo don hernando de acuña con sus figuras yluminados, cubierro de cuero colorado y blancon. (AGS. CMC. $1^{2}$ época. Leg. 1145. Fol. 130, sf). Ha perdido la encuadernación original, sustituida posteriormente por una simple cubierta de pergamino, pero por su descripción y la semejanza que tiene con otros libros, parece que fue Cristóbal Plantino, entonces 
debe considerarse como el texto que sirvió para realizar la impresión definitiva, tras la revisión previa del monarca. Finalmente, la obra salió impresa en 1553, en una edición de lujo ${ }^{54}$. Francisco Duarte cuenta al príncipe Felipe como Carlos $V$, retirado en Bruselas y como si presintiera próxima la muerte, se dedicaba a leer unos comentarios de los salmos de David (probablemente los de la citada edición de Tittelmans), y El caballero determinado, en impresión encargada por el monarca a Calvete, y le advierte de que Calvete se proponía enviar a Gonzalo Pérez una relación más detallada acerca de su trabajoss.

El cuidado que se puso en esta impresión, así como el íntimo interés de Carlos $\mathrm{V}$ en ella, recuerda mucho al exhibido décadas atrás por su abuelo Maximiliano en la confección de su biografía. Como es bien sabido, el Caballero determinado parte de la consideración de la vida humana como milicia, como palenque en el que había que justar para lograr primero la fama y después la salvación. Era un tópico de la cultura aristocrática y caballeresca del Renacimiento. Un «ars moriendi» cuyo argumento gira en torno a los lances que sostienen Felipe el Bueno, Carlos el Temerario, María de Borgoña, Isabel la Católica, Felipe el Hermoso, Fernando el Católico y Maximiliano I, en la palestra de Atropos con sus caballeros Accidente y Debilidad, un combate abocado al fracaso, pero tras el cual se discurre la manera de afrontar la muerte sin temor, y trocarla en apoteosis de la vida ${ }^{56}$. Esta visión caballeresca del César ante la muerte era consecuente con sus propias raíces culturales y con su educación borgoñona, pero era, sobre todo, concordante con la temática del Theuerdank o del Weissküning, de su abuelo. Es más, tanto el dictado de sus memorias a van Male, como la posterior participación de éste en la corrección del Caballero de-

sólo un afamado encuadernador francés asentado en Amberes, quien realizó las tapas. Felipe II conservó este manuscrito en su biblioceca hasta su muerce, destinándose entonces a la almoneda..

34 Vid. PeEters, J-F. "A propos des éditions du Caballero determinadom, Les Lettres Romanes, 19 (1959), pp. 69-70; y «Les éditions espagnoles du "Chevalier Délibéré" d'Olivier de la Marche». De Gulden Passer. 38 (1960), pp. 178-192.

ss Citado en TYLLER, Royall: Calendar of Letters, Despatches, and State Papers, relating to the negotiations betwen England and Spain, preserved in the arcbives at Vienna, Simancas, Befançon and Brussels, Londres, 1916, IX, p. 225: «He (S. M.) has been occupied for many days in reading the Psalms of David and having them recited to him, with their commentaries. He has had a new edicion printed; and the care of it is in the hands of Estrella, one of your Highness's servants, who is to overlook the impression. I think he has sent or will send to Gonzalo Pérez a more detailed account of it, and of now he ditected the printing of the book called El Caballero Determinado on his Majesty's behalf, and the other ttisfles we all know of. I will not dwell upon these unimportant matters». Francisco Duatte al Príncipe Felipe. (Sevilla, 9-sep-1553). Original en español. AGS. E. Leg. 98.

so Sobre la influencia en Carlos V de esta obra, en la edición de Calvete, vid. VARELA, Javier: La muerte del rey. El cenemonial funerario de la monarquia española 1500-1885., Madrid, Turner, 1990, Pp. 36-37; Clavería, Carlos: Le Chevalier deliveré de Olivier de la marche y sus versiones españolas, Zaragoza, 1950; CHECA CREMADES, Fernando: «El caballero y la muerte. (Sobre el sentido de la muerte en el Renacimiento)», Revista de la Universidad Complutense, (1982), 4, pp. 242-257.

Hispenie, LX/3, núm. 206 (2000) 911-944 
terminado, traducido por el Césart ${ }^{57}$, parecen corresponderse con un proyecto autobiográfico de gran amplitud, en el que las "Memorias", que van Male llevó consigo a Yuste, debían ser el borrador, sobre el que él, posteriormente, al estilo de los humanistas de Maximiliano, el propio van Male, Acuña, Calvete y Arnold Nicolai, compondrían una biografía cesárea, a manera de la epopeya versificada que crearon aquellos. El Chevalier, en este proyecto, constituiría probablemente la última parte. Como es sabido, Felipe II estaba al corriente de estas memorias, que ordenó arrebatar al belga en cuanto murió su padre, temeroso de que tanto su contenido como su destino fueran perjudiciales para la Corona, o, quizá, coherente con los escrúpulos de conciencia que su padre le había confesado al redactar tal autobiografía ${ }^{58}$.

Frente al Chevalier, la lectura de los salmos partía de unas consideraciones religiosas más generalizadas en la época. Tittelmans era considerado como el mejor comentarista de esta parte de la Biblia, y la lectura de sus salmos, que él había dedicado a Carlos $\mathrm{V}$, era recomendada en los ars moriendi de la época. La reflexión sobre su contenido era una manera de acercarse a Dios en el trance de la muerte, en particular la de los salmos penitenciales. Carlos V siempre había sido muy devoto de la lectura de esta parte del salterio, como lo indica su inclusión en varias de sus libros de horas ${ }^{99}$, y en Yuste acrecentó esta costumbre devota. Como recuerda Sigüenza, tras la misa que habitualmente se hacía en el monasterio jerónimo por la emperatriz, Carlos gustaba de rezar unos salmos penitenciales, «de rodillas delante el altar, y hallauanse todos los flamencos a esta Missas ${ }^{60}$. Que el monarca tuviera dos ejemplares de esta obra de Tittelmans en Yuste, así como otro en Simancas, resulta sorprendente, aunque consecuente con su devoción sálmica. Las penitencias del rey David, su espejo bíblico, no debían ser de poco consuelo para purgar sus propios pecados.

En otros vericuetos del alma se introducía Carlos V con el De consolatione philosophiae, de Severino Boecio, que, como decíamos más arriba, tenía en un manuscrito en francés (que Felipe II conservó hasta su muerte) ${ }^{61}$, y en dos edi-

37 García Simón, El ocaso del emperador, op. cit, p. 78 , n. 24

SB Fernández Álvarez reconstruye de manera muy documentada la existencia y vicisitudes de las "memorias" de Carlos V en su edición y estudio de su testamento.

59 DoCAMPO, «Imagen religiosa y devoción privada: los libros de oraciones de Carlos $\mathrm{V}$ ", op. cit., pp. 219-224.

so SIGÜENZA, José de: Historia de la Orden de San Jerónimo, Madrid, 1909, Biblioteca de Autores Españoles, 12. Tomo II, p. 152.

61 En el inventario Inventario de 1574 figuran varios Boecios, dos se entregaron a la Laurentina, uno cubierto en terciopelo azul y otro, en dos tomos, en terciopelo carmesí, pero el de Carlos V quedó en palacio: : «b 1 Orro Boetio de consolacion en pergamino de mano con cubierta de terciopelo carmesi», entre los libros de filosofía en francés y folio a cargo de Serojas. (RBME, ms. \&-II-15, fol. 299v). No se entregó a la Laurentina posteriormente, pues no figura en el Catálogo de manuscritos en romance del Escorial (s. XVII), donde si aparecen los dos Boecios antes citados: «Boecio. De la Philosophal Consolacion. (III-P-4) y el mismo libro en dos tomos. III-O-1516, y ya perdidos. Sí figura, en cambio, en la Testamentaría de Felipe II (1598): «Boecio: De Consolation, escrito en 
ciones, una italiana de Anselmo Tanzo, de $1527^{62}$, y otra castellana de fray Alberto de Aguayo, de $1521^{63}$, traducción castellana muy elogiada en la época, tanto por Juan de Valdés en su Diálogo de la lengua ${ }^{64}$, como por Ambrosio de Morales, quien la definió de esta guisa: «En un tan buen estilo, que cualquiera que tuuiere buen voto, juzgará, como está mejor en nuestra lengua que en la Latina” ${ }^{65}$. Escrito en la cárcel, mientras esperaba su ejecución, el filósofo romano compuso el De consolatione para procurarse consuelo sobre la inconstancia de los favores de los príncipes y la inestabilidad de los afectos de los amigos, meditaciones muy apropiadas para un rey. Boecio la redactó recogiendo los principios platónicos, muy influido por Proclo, y estoicos, a través de Séneca; y en sus páginas enseña la miseria de todas las felicidades eternas y demuestra que sólo existe el reposo y la paz en la virtud, enviándose al hombre las penas y las tribulaciones por la voluntad de Dios, con el fin de salvarle. Al final de su trayecto vital, Carlos $V$ podía encontrar en la lectura de esta obra, que -como hemos dicho- acopió en tres lenguas diferentes, un camino para poder contemplar su reinado y su vida con una mirada de estoicismo, siguiendo como hiciera Boecio, aquella máxima filosófica de Platón: «Si deseas contemplar con clara luz la verdad, toma la senda por el atajo, echa las alegrías, lanza ei temor y ahuyenta la esperanza, para que no se presente el dolor. Nublada está la mente y sujeta por frenos donde tienen imperio aquellas cosas».

Meditar, a esta acción dedicó Carlos V buena parte de sus pensamientos en Yuste, a meditar sobre la vida para preparase para la cercana muerte. Boecio exa sólo el primer escalón, incluso en una escala cronológica: eran los orígenes filosóficos, gentiles, del ars moriendi, cristianizados en el Medievo. Después,

frances, en folio, en pergamino; encuadernado en cartones y terciopelo carmesi. - En 20 reales. (E)", entregado a Hernando de Espejo con destino a la almoneda. (ANTOLín, "La tibrería de Felipe II», op. cit., CXVIII, p. 45). Es muy probable que se corresponda con el conservado en la BNM, que Jean de Meum escribió e iluminó para el rey Felipe IV de Francia. Vitrina 23-13, y que todavía conserva una encuadernación entelada de papelón cubierto con terciopelo carmesí, surcado con finos pespuntes verticales de hilo negro. Procede de la biblioteca del duque de Osuna.

62 BOECIO, Boetio Severino di consolatione Philosophica volgare, Nuouam(n)te restisto et di molti errori porgato opera al tutso dignissima Eccelente et Bella. Don Anselmo Tanzo al Pio Lettore. Venecia, Giovanni Antonio di Sabio y hermanos, 1527, 8 . RBME, 17-VI-18. Encuadernación flamenca en cuero clorado y papelón. Dos triples filetes en seco enmarcan las tapas, con un floroncillo dorado en las esquinas de la entrecalle, y otro en el centro. Lomo con filetes en seco en los nervios y una cruz griega dorada en cada entrenervio.

63 BOECIO, Libro de boecio semerino intitulado de la cofn\}solacio\{n\} de la pbi lasopbia: agora nuewamente tradkzido de latin en castellano por estilo nu (n) la ante visto efn\} expaña. va el metro efn\} coplas $y$ la prosa por medida. Sevilla, Jacobo Cromberger, 1521, $4^{\circ}$. RBME, 24-XILI-2. Encuadernación plateresca de transición en becerro negto y papelón, gofrada. Señal de dos cintas. Parrilla y corte dorado escurialense. Se transluce un corte colorado o jaspeado original.

64 Valdés, Juan de: Diálogo de la lengua, Madrid, Cátedra, 1987, Letras Hispánicas, ${ }^{\circ} 153$, p. 245.

6s En la edición de las Obras de su tío Pérez de Oujva, Fernán: Córdoba, 1585, fol. 11r.

Hispania, LX/3, núm. 206 (2000) 911-944 
avanzando un poco en el tiempo, pero mucho en la religión, Carlos $V$ seleccionó las famosas Meditationes agustinianas. Sin duda, se trataba de las difundidas Meditaciones y soliloquios y manual del bienaventurado San Agustín, obra impresa por vez primera en castellano, en 1511 , y reeditada sucesivamente en vida del emperador, hasta 1553. No hemos logrado identificar qué edición en concreto era la que Carlos $\mathrm{V}$ leyó, pues, si bien entre los libros de teología que Felipe II cedio al Escorial, figura un ejemplar de esta obra, impresa en Sevilla en $1550^{66}$, ésta había sido de la princesa doña Juana. Sea como fuere, su lectura por el César es muy significativa. Aunque apócrifa, las Meditaciones habían modelado todo el pensamiento ascético español de la época. No sólo porque vulgarizó una religión en la que se enseñaba al hombre a tomar una actitud de profunda humildad, e incluso de sometimiento, ante la gracia, sino también porque acuñó un lenguaje que conmovió profundamente a los españoles, e incluso al propio César, "abdicado» y «rendido" ante soliloquios pseudoagustinianos, como éste:

«Tarde te amé, oh hermosura tan antigua y tan nueva, tarde te amé y tú estabas dentro y yo fuera y aquí te buscaba... Rodeaba todas las cosas buscándote... Pregunté a la tierra si era mi Dios y dijome que no, y todas las cosas que en ella estaban confesaron lo mesmo. Pregunté al mar ya los abismos y a los animales réptiles que en ellos son, y respondiéronme: "No somos tu Dios...", y dije a todas las cosas que están fuera alrededor de mi carne: "Decidme nuevas de mi Dios si algo sabéis", y todas alzaron gran voz y dijeron: "El nos crió"s.

San Juan de la Cruz y Santa Teresa de Jesús traerán a colación este mismo texto en su Cántico espiritual y en su Vida y en las Moradas, como un grito de angustia ante la búsqueda infructuosa de Dios. $Y$ esta busca era la misma que Carlos V había iniciado con su viaje a Yuste. En este camino por la propia vida, en la que el César trataba de «armarse» con las mejores celadas, escudos y lanzas que la Fe le podía proporcionar en su último torneo, sus cansados ojos se detuvieron también en la lectura de otros dos libros de molde, en francés, sobre la meditación. Ambos volúmenes, que se conservan en El Escorial, se corresponden con una de las más importantes obras de la espiritualidad francoflamenca, el Liure tresutile de saincte meditation de lbomme, de Roberto Ciboule (1458- c. 1511), publicado por vez primera en 1510. Reeditado en 1555 por fray Pierre Lefebure, franciscano confesor de Carlos V, a quien dirigió obra «tan útil», el monarca recibió dos ejemplares, «de vn tamaño guarneçidos de vna manera», extraña descripción que parece hacer referencia a que sólo uno de ellos estaba encuadernado, y el otro no, o con cubiertas diferentes. Y así es como entraron en El Escorial, uno, ahora en la Habitación de Felipe II, encuadernado en cuero y papelón, con cuatro águilas bicéfalas coronadas, doradas,

o6 ANDRÉs, «Entrega de la librería real», op. cit., p. $73, \mathrm{n}^{\circ} 1373$. 
en las esquinas, y una placa de lacerías vegetales en el centro, también en oro ${ }^{67}$, y otro, duplicado, que fue reencuadernado con la típica cubierta escurialense, con indicaciones de que sus diferentes partes estaban por separado. De la difusión de esta obra devota en el entorno de Carlos V nos da idea el hecho de que su hermana María también se llevara a España un ejemplar de esta obra (como también otro del caballero determinado ${ }^{68}$ ), y encuadernado de manera muy parecida al de Carlos $\mathrm{V}$, con cuatro águilas bicéfalas doradas ${ }^{69}$. La semejanza en las cubiertas hace suponer que los dos libros fueron obsequiados por el franciscano a ambos, antes de su partida a España.

La presencia de esta obra de Ciboule en la biblioteca de Carlos V, y ligada de manera tan directa a una personalidad de su entorno religioso, como su propio confesor, nos enmarca de nuevo la mentalidad religiosa del César en Yuste. Establecida desde coordenadas un tanto apriorísticas, como la continuada referencia al Enchiridion de Erasmo, o a las corrientes de ascetismo pujantes entonces en España, la saincte meditation de lbomme, nos remite a las propias raíces culturales de "Charles de Gand", el mundo franco-flamenco de su infancia, en las que el Chevalier délibéré, de Olivier de la Marche, o autores como Ciboule, entroncaban de una manera más íntima con su pensamiento. Pero su escala ascética en la meditación todavía no había terminado, Carlos V se había movido espiritualmente siempre por el camino de la devotio moderna, que el humanismo renacentista de Erasmo había contribuido a difundir por toda Europa con su Enchiridion militis christiani. Es muy probable que el emperador hubiera tenido entre sus libros esta obra, si no en latín -idioma en el que no era excesivamente versado, sí en alguna de las múltiples ediciones en francés o en castellano que se imprimieron durante su reinado. A este respecto, sabemos, por ejemplo, que tanto su esposa como su hijo fueron lectores del Encbiridion

\footnotetext{
67 CIBoule, Robert: Robert y Pierre Le Febvre, Liure tresutile de saincte meditation de l thomme sur soymesmes, contenant en trois parties declatation de tout ce qui est en lbomme, composé par venerable docteur Maistre Robent Cibole, iadis chancelier de nostre dame de Paris, nouuellement neweu, corrigé, \& augmenté par F. Pierre le Febure, de lordre des F. Mineurs de lobseruance, confesseur de lEmpereur Charles cinquierme. Est adiouste $\mathcal{E}$ insere a la troisiesme partie un traicté des graces $\varepsilon$ operations du sainct Esprit, $E$ des oppugantions E malefices contraires de lesprit maling. Autbeur le susdit F. Pierre. Sin colofón. Lovaina, Antoinne Maria Bergangne, 1555. $4^{\circ}$. Prefacio de fray Pierre Le Fevre a Carlos V (Bruselas, 1 de agosto de 1555). RBME, Habiración de Felipe II. Encuadernación con el águila bicéfala dorada en lis ángulo y placa vegetal en el centro. El orro ejemplar bajo la signatura RBME, 34-V-2, $\mathrm{n}^{\circ} 1$. Encuadernación escurialense. En la portada del siguiente «libro» de la obra (RBME, 34-V-2, $\mathrm{n}^{\circ} 2$ ), nota a mano: «juntese con la primeran, lo que indica que estaban por separado.

68 En el inventario de sus bienes: «Yten vn libro mediano en tablas de papel con labores de esmaltes, contrahecho, es el cavallero determinado traduçido de françes en español por don fernando de acuñan. AGS. Contaduria Mayor de Cuentas. $1^{2}$ época. Leg. 1093, fol. 204v.

69 Este ejemplar se conserva también en la Laurentina, con el ex libris «Royne Marien. RBME, 69-VLI-33, $n^{\circ} 1$
} 
erasmiano ${ }^{70}$, devota lectura que no pudo ser ajena al propio Carlos, "caballero cristiano» él mismo. No en vano, García Simón califica el fallecimiento de Carlos $\mathrm{V}$ en Yuste como "muerte erasmiana", y propia de una persona que conocía la Prateparatio mortis, del Roterodamo. La observación ya la hizo antes Bataillon $^{71}$. Que este libro no estuviera entre los de la biblioteca carolina no significa que fuera de alguno de sus criados, y que le hubiera sido prestado o leído durante su estancia en Yuste.

En todo caso, Carlos V sí tenía entre sus «libros devotos» una obra de Erasmo, su Precatio Dominica ${ }^{72}$, que iba incluida dentro del pequeño librito de Precationes Biblicae, antes citado. Esta paráfrasis erasmiana del Pater Noster, que Bataillon define como un ecántico al Dios de gracia con un sentimiento de humildad y de confranza sin límites» (p. 285), fue el modelo que Valdés, Constantino, Porras, Meneses y Carranza siguieron libremente en sus obras, al mismo tiempo que se inspiraban en una tradición anterior (pp. 587-588). El librito, de escaso valor, se vendió en almoneda, pues el Índice de 1559 sólo prohibió la Declaración del Pater Noster en castellano. Peto, es precisamente de dos de éstos nuevos autores espirituales, Constantino Ponce de la Fuente y fray Luis de Granada, de quienes tenía obras en el monasterio. Del primero poseía un ejemplar impreso de su Doctrina christiana, y del segundo otro de su (y no podía ser de otra manera), Meditación. Ambos autores habían reelaborado, desde el pensamiento humanístico, la espiritualidad erasmiana, y en ellos creyó Carlos $V$ encontrar la culminación de aquel proceso iniciado en Boecio. De la gran difusión que estos autores tenían por entonces en la corte, nos da idea el hecho de que el propio Constantino hubiera sido llamado en 1548 por el príncipe

70 En el inventario de los bienes de la emperatriz Isabel (1539): « $\mathrm{Vn}$ libro que se dize ynquiridion o manual del cauallero christiano enforrado en cuero vayo,n. Y en 1541 se compró para su hijo Felipe « va ynchiridion de Erasmo en romançe». Vid., GonZALO, La «Libreria rica» de Felipe II, op. cit., p. $676, \mathrm{n}^{\circ} 1185$.

71 GARCía SIMON, El ocaso del Emperador, op. cit., p. 146. Escribe Bataillon al respecto: "No sé en qué tradición se apoya un traductor francés del Encbiridion y de la Preparación para la muerte cuando dice que Carlos V, retirado en Yuste, tenía por devocionario el Manual de Erasmo (Manuel du soldat cbrestien, seguido de la Préparation a la mort [trad. Por Cl. Du Bosc de Montandré], París 1711, Prólogo). ¿No habrá manejado el Emperador un volumen compuesto del Encbividion, la Paraclesis y la Preparación, edición de Amberes, 1555? Desde luego, la escena de su muerre, tal como la describen los delatores de Carranza, recuerda un pasaje de la Preparación en que dice Erasmo que el más eficaz consuelo del moribundo es no apartar los ojos de la fe del que se dio todo a nosorros y es abogado nuestro ante Dios; y le exhorra a guarecerse en las cavernas de aquella piedra, o sea en las llagas de Cristo, para protegerse de Satanás». BATAILION, Marcel: Erasmo y España. Estudios sobre la bistoria espiritual del siglo XVI, Madrid, Fondo de Cultura Económica, 1986, p. 572, n. 47.

72 PRECATIONES Biblicae sanctoru(m) Patrum, Patriarcbaru(m), Prophetarum, Iudicium, Regu(m), Virorum et Mulierum illustrium Veteris et Noti Testamenti. quae bis accessere, sequens pagina com monstrabit. LVGDVNI, sub scuto Coloniensi, 1545. Lyón, Jean y François Frellon, 1545, 16. Las precaciones que incluía eran de varios profetas (Esaias, Jerenias, Ezequiel y Miqueas), unos salmos de David contra tiranos, la explicación del Símbolo Apostólico y la Precatio Dominica de Erasmo. 
Felipe para que fuera su predicador, oficio que aquel aceptó y en cuyo desempeño se embarcó en el Felicísimo viaje. Completaba esta selección de libros de espiritualidad la Doctrina christiana de fray Pedro de Soto, sin duda su Compendium Doctrinae Catholicae (Ingolstad, 1549), ejemplar que Soto, confesor y consejero del monarca entre 1542 y 1548 , debió remitir al monarca; y unos comentarios manuscritos sobre el salmo "In te domini speravi", que compuso fray Tomás Portocarrero, también dominico y predicador de Carlos V, como Soto. Ambas obras se vendieron en la almoneda posterior de los bienes del emperador, siendo ya casi imposible su localización. Sin embargo, la segunda se encontraba a principios del siglo XVII en la biblioteca madrileña del Marqués del Carpio, donde la vio el erudito Tomás Tamayo de Vargas, según recoge décadas más tarde Nicolás Antonio ${ }^{73}$.

Sorprendentemente, no encontramos en Yuste, como tampoco en Simancas, una Biblia. Esta ausencia es extraña, porque se trata de la lectura básica de todo cristiano. Sin embargo, creemos que sí hubo una Biblia en el monasterio extremeño, pero en lengua francesa. Al parecer, Carlos V tenía un permiso del Santo Oficio para leer las sagradas escrituras en este idioma, autorización que su médico, Henry Mathise, quién se trajo de Flandes una Biblia en francés, también trató de obtener. Advertido por Reglá de que estaba prohibida su lectura en España, escribió a Vázquez de Molina para lograr un permiso ${ }^{74}$. Pero el secretario nada pudo hacer ante los inquisidores, y tras recibir su respuesta, el médico belga quemó, en presencia del confesor, la biblia. En este contexto, es muy probable que tanto la insistencia de Reglá, como el suceso de Mathys, obligaran al emperador a quemar también su biblia, temeroso de que su posesión pudiera entorpecer el camino hacia la salvación que había emprendido. De

73 Sobre Portacarrero, dice Nicolás Antonio: « Thomas PorTocarrero, F.: Dominicanus, concionator regius, scripsit vernaculo sermone: Declaración del Psalmo LXX. Ms. Quam vidit D. Thomas Tamajus, \& servatur hodie, ut credimus, in bibliotheca marchionis del Carpio Matriti”, Bibliotheca Hispana Nova, Torino, 1963, II, p. 311. No indica Antonio donde cita Tamayo este manuscrito, pero es de suponer que se trate de su Junta de libros la mayor que España ba visto en su lengua basta 1624, manuscrita en la BNM, donde escribe: "THOMAs PVerToCarrero, $\mathbf{M}^{\circ}$ F.: Dominico Predicador de su Mag. Declaracion del Psalmo 70. Ms. 4. « (BNM, Mss, 9753, folio 95v).

74 «Tengo que suplicar a Vuestra Señoria una merced, y será para mí muy grande. $Y$ es que Vuestra Señotía sabrá como traje de Flandes una Biblia en francés. Y cuando yo estaba cansado de leer o estudiar cosas griegas y latinas, holgábame con leer algunas veces en ella. Agora díceme el nuestro confesor, que acá en España no se puede tener, por ser en francés. Yo no querría errar; pero bien sé que en Flandes la podemos tener en cualquiera lengua. Y, con permisión de Su Majestad, suplico a Vuestra Señoria entienda de los Inquisitores, si quieren que yo la tenga y la lea por mi contentaniento; y, si no, luego a la hora la quemaré, porque acá no pretendo otra cosa, sino obedecer a lo que ellos me mandaren. $Y$, por entenderla, no me importa más que sea francesa o italiana, o latina, o griega, oflamenca, o española, aunque acá con Su Majestad no hablamos sino francés... De Yuste, a 30 de mayo, 1558. La Biblia que yo digo, no tiene sino el texto solo, en pequeña forma,». CADENAS Y VICENT, Vicente: Carlos de Habsburgo en Yuste. 3-11-1557 - 21-IX-1558, Madrid, Hidalgúa, 1984, p. $65, \mathrm{n} 5$. 
aquí que a su muerte no se cite en el inventario de sus bienes. Sus hermanas María y Leonor eran también asiduas lectoras de la biblia en lengua francesa ${ }^{75}$, y los tres hermanos bebían, a este respecto, de una misma tradición cultural.

Que el mismo Carlos que instigaba a la persecución sin contemplaciones de los brotes de herejía protestante en España, fuera en Yuste un lector del Erasmo, del doctor Constantino, de fray Luis de Granada y de la biblia en lengua romance, es una paradoja que nos revela el brusco giro que se produjo en la espiritualidad de la época. De repente, todo un mundo de piedad se hizo sospechoso, y en el monasterio extremeño se vivió un episodio de aquella «histeria colectivan. Recordernos que ya en el momento de su óbito, la presencia de otro de los pronto perseguidos, el arzobispo Carranza, levantó grandes suspicacias con sus palabras. A Carlos, al parecer, ya le habían llegado desde Valladolid noticias que vinculaban al prelado con los conventículos protestantes recién descubiertos en España. Resulta, no obstante, parad6jico, que a pesar de sus duras admoniciones para que el brote herético fuera extirpado sin piedad, no supiera que dos de esos "herejes", Constantino y Granada, iluminaban su alma en el camino que le conduciría al encuentro de "Atropos». La herejía había llegado a Yuste en su propio equipaje. Cuando el César falleció, los autores del inventario anotan que el libro de Constantino fue llevado a «casa del arzobispo de Sevilla», Valdés, inquisidor general, empeñado ya en el proceso del predicador sevillano, y que el tratado de Granada, simplemente, fue quemado.

Menos sospechosos eran sus libros litúrgicos. En una bolsa de sayeta negra guardaba dos breviarios, uno de San Jerónimo y otro Romano, nuevo, que, junto con un Oficiolo de la Semana Santa, guardado también en otra bolsa de sayeta, "vn misal pequeño antiguo", unas Horas escritas en pergamino e iluminadas, con manillas de oro, dos salterios pequeños, dos misales, y el ejemplar en $16^{\circ}$, ya citado, de las Precationes Bibliae sanctorum (Lyon, Jean y François Frelion, 1545), servían al emperador cuando rezaba. En cambio, para un uso más público, quizá para servir a los frailes cuando oficiaban los oficios litúrgicos en la cámara imperial, reservó Carlos $\mathrm{V}$ dos códices iluminados, el uno un Oficio de la Navidad, y el otro sin identificar. Resulta difícil identificar que Breviarios $y$ oficios son los que Carlos V usó en Yuste. Como hemos visto, el famoso Breviario que lleva su nombre quedó en Simancas, y en los inventarios posteriores de Felipe II los libros litúrgicos se entremezclan, perdiéndose su origen. No obstante, en la Laurentina se conserva un Breviario romano, de 1529, con una encuadernación flamenca muy semejante a otras de la biblioteca de Carlos $\mathrm{V}^{76}$. Su hermana María también poseía un breviario impreso en dicho año, pero,

75 LEMAIRE, "La bibliothèque des imprimés", op. cit., p. 121.

76 Brexiarium Romansm: luculentissimo nu $(n) c$ caractere impressum: $c k(m)$ no $(n)$ nullis peruigili curo insertis additamentis ac wbilibet legendaru $(m)$ compleme $(n)$ tis: ora $(n) t i u m$ dewotioni plurimum acco $(m) m a d t s: . .$. Lyón, Denis Harsy, 1528-1529, 8. RBME, 10-VI-2. Encuadernación renacentista flamenca en cuero marrón y papelón, dorado. Tres filetes dorados con un circulillo en las esquinas, enmarcan un juego de entrelazos dorados, con flores y ramas. En el centro una cruz de David. 
aunque se dio a un obispo de su séquito, quizá sea él mismo. Por eso no nos atrevemos a confirmar que este Breviarium sea el de Carlos V en Yuste.

Menos dudas hay con respecto al libro de Horas, las mismas en las que según Sigüenza-, todas las mañanas rezaba acompañado de su confesor fray Juan Reglá: «A la mañana, abierto el aposento, conforme el dia y el tiempo, entraua luego alla su Confesor, ayudauale a rezar si la gota no le tenia muy apretado; trataua algunas santas consideraciones de las que tenia platicadas como buen frayle. Deziale los misterios que en aquellas Horas se representauan, para que de tan buenos pensamientos llena el alma a la mañana, tuuiesse que pensar todo el dia. Duraua este exercicio hasta que el Cesar queria, o alguna nessidad lo desbarataua " 77 . Este libro de Horas, único que se cita en el inventario de Yuste, (en Simancas había otras) debe identificarse con el llamado Libro de Horas de Carlos V, hoy en la Biblioteca Nacional de Madrid, Vitrina 24-3, y que en 1614 Felipe III regaló al cardenal Francisco de Joyeuse. De este obsequió queda constancia en una inscripción en letras doradas, en la hoja de guarda del códice, y en la segunda hoja de guarda se añadió: «Hic liber fuit Magni Imperatoris Caroli $V$ ". En el siglo XVIII pasó a propiedad del Cardenal Zelada, con cuya biblioteca toledana ingresó en la Nacional en $1869^{78}$.

Este códice no fue escrito e iluminado para Carlos V, pues se trata de una obra salida de talleres parisinos en época de los reyes Carlos VIII y Luis XII. Su predilección por él merece una explicación. Conociendo su acendrada mentalidad dinástica, probablemente heredó el libro de su padre Felipe el Hermoso, o de su tía Margarita, y de aquí su deseo de conservarlo hasta la muerte. Pero también hemos de dirigirnos hacia la iconografía presente en el libro, sobre todo si nos detenemos en los tres grandes cuadros a doble página que dan carácter propio al manuscrito: $\mathrm{La}$ entrada victoriosa de Heraclio en Jerusalén con la cruz de Cristo rescatada de los persas (ff. 136v-137r), — que enlazaría con el papal de defensor de la Cristiandad desempeñado por Carlos como Sacro Emperador- , la victoria de David sobre Goliath (ff. 176v-177r) - escena plenamente vinculada a la iconografía bíblica del César, nuevo David-y, sobre todo, el encuentro de los tres caballeros con la muerte, que sirve de tema a la meditación del ermitaño (ff. 218v-219r), y que en la mentalidad de Carlos V, retirado en Yuste, alcanza una dimensión personal de gran transcendencia. Es como si hubiera visto en estas tres escenas un compendio de su propia vida.

En Yuste pudo haber, no obstante, otro libro de Horas, magníficamente iluminado hacia 1540 , y que se conserva en la Pierpont Morgan Library ${ }^{79}$. El

77 SigüENZA, Historia de la Orden de San Jeninimo, op. cit., II, p. 151.

78 DOMínguez RoDrfgueZ, Ana: Libros de Horas del siglo XV en la Biblioteca Nacional, Madrid, Fundación Universitaria Española, 1979, pp. 82-105; e DELAUNAY, Isabelle: «Les Heures d'ecouen du Musée National de la Renaissance: échanges entre manuscrits et imptemés, autour de 1500", Revue du Louvre 4, (1993), pp. 16 y ss.

t9 Officium B. V. Mariat, cum aliis devotis pracationibus. Vitela (c. 1540), $288 \mathrm{ff}$ (17 x $10 \mathrm{~cm}$ ). Pietpont Morgan Libray, M. 696. Sobre estas Horas vid. The Pienpont Morgan Library. A Review of the 
folio inicial presenta un escudo de Carlos V, con el título «Officium dive Virginis Mariae. Cum aliis devotis precationibus Caroli Quinti Romanorum Imperatorum Regis Hispaniarum», y le siguen 30 iluminaciones a folio entero, varias de ellas con retratos de Carlos V, de su tía Margarita de Austria, de Felipe II, María de Borgoña, Carlomagno y otros. Es dudoso, en nuestra opinión, que, como se señala en el catálogo de la Pierpont Morgan Library, fuera regalado a Gaztelu tras la muerte del César, pues Felipe II no obsequió ninguno de los libros que recibió de su padre. Nos parece más probable que fuera el propio Carlos quien, antes de morir, en Yuste o en Flandes, diera a su fiel secretario estas horas. De aquí que en su inventario sólo aparezcan unas Horas, las de la Biblioteca Nacional.

Pero, como es bien sabido, el retiro de Carlos $\mathrm{V}$ a Yuste no fue tan fúnebre como pudiera parecer, sino que al contrario, gustaba de distraerse en múltiples actividades lúdicas, gastronómicas e intelectuales. Aquí nos interesan estas últimas. La afición del César por la relojería se trasladaba a los instrumentos astronómicos, cuadrantes, astrolabios, y cartas de marear que poblaban su cámata con insolencia, recordando a su dueño sus múltiples viajes. Junto con éstos, en los anaqueles de su librería descubrimos un ejemplar del Astronomicum Caesaris, de Apiano, cubierto de terciopelo negro y con cinco chapas de plata doradas en las tapas ${ }^{80}$, que venía acompañado de un manuscrito en castellano que el astrónomo real, Alonso de Santa Cruz, hizo sobre el Astronomicum. Sin duda se trata de la guía inicial que le solicitó Carlos V en 1541, y que luego el cosmográfo, al no ser lo suficientemente sencilla para el monarca, anduvo reto-

Growth, Development and Activitier of the Library During the Period between Ist Establishment as an Educational Institution in February 1924 and the Close of the Year 1929, Nueva York, 1930, pp. 69-70; RICCI, Seymour: Census of Medieval and Renaissance Manuscripts in United States and Canada, Nueva York, 1961, II, p. 1483; y WIECK, Roger S.: Painted prayers.the books of hours in medieval and renaissance ant, Nueva York, George Braziller, 1997, p. 18, $\mathrm{n}^{\circ} 8$ y p. $108, \mathrm{n}^{\circ} 84$. Se considera que fue de los que tuvo en Yuste, ya que fue propiedad de su secretario Martín de Gaztelu. Pero también podría tratarse de las Horas de nuestra señora, que estaban en Simancas, en poder de María Escolastres, y en octavo como éstas. En 1576 estaba en poder de Martín de Gaztelu, secretario de Felipe II. En 1734 era de Cristóbal Fernández de Córdoba, Conde de Sastago, más tarde, en 1881, estaba en poder de Don Marcial Lorbés de Aragón, de Sadaba (Zaragoza), y fue adquirido para la Pierpont Morgan en Londres, en 1925. Encuadernación del siglo XVII.

so APIANO DE LEYSNICK, Pedro: Astronomicum Caesareum. Tículo dentro de una cartela de grutescos y puti sosteniendo tondos con águila imperial, todo coloreado, y debajo grabado de una esfera astronómica de dragones, también coloreado. Ingolstad, Pedro Apiano, 1540. Fol. Mayor. Inventario de 1574: «a $121^{*}$ Astronomici Caesare $\langle\mathrm{n}\rangle\langle$ de $\rangle$ Perri Apian $\langle\mathrm{i}\rangle$ impress $\langle u m\rangle\langle\mathrm{e}\rangle$ In Golstadij 1540 , con sus figuras e instrumentos con vna <figura > cubierca de terciopelo negro y cinco tachones dorados de cada lado las figuras illuminadas, fue del emperador", entre los libros de matemáticas en latín y en folio a cargo de Serojas. (RBME, ms- 8 -II-15, folio 283v). Aunque se indica que pasó a la Laurentina, y así fue, lo cierto es que altí sólo se conserva ya el que perteneció al príncipe don Carlos, y que, como duplicado, en 1576 se destinó para uso de los frailes, en las celdas. Es posible, no obstante, que el de Carlos V retornara a palacio, o pasara en el siglo XVIII a la Biblioteca Real, después Nacional, donde actualmente existe otro Astronomicum. 
cando hasta convertirse en el Astrónomico Real, de 1556. Por allí andaba también un Tolomeo, sin descripción de lengua o de si era impreso, pero que debía ser de poco valor, pues se destinó a la almoneda. Sobre estos libros remitimos al interesante estudio de Esteban Piñeiro, Vicente Maroto y Gómez Crespo, antes citado.

La otra afición del César por la filosofía natural, en particular por la botánica, se refleja en los tres libros que tenía, pintados en dos de ellos, «diferentes arboles e yeruas, hombres e otras cosas de las yndias", y en el tercero "diferentes yeruas». Resulta difícil descubrir el origen de estos manuscritos. Podría pensarse en un obsequio de Gonzalo Fernández de Oviedo, autor de una Historia natural de las Indias, pero también en Cornelio Baersdorp, protomédico de su hermana María de Hungría, magnífico botánico. Decimos esto porque acompañó a su señora hasta España, y asistió al César en su última enfermedad, reclamado por éste. En la biblioteca de María encontramos precisamente tres volúmenes sobre hierbas, plantas y frutos de las Indias, encuadernados también en terciopelo carmesí. En su inventario, no se indica que fueran prestados a Carlos V, cuando su hermana le visitó en Yuste, pero la semejanza de materias y encuadernaciones nos hace suponer, o que fue así, o que el César había recibido una copia. La afición por esta materia era tan grande en el monarca que, según nos cuenta Sigüenza, solía conversar con sus médicos de cuestiones de hierbas, medicinas y naturaleza, y que en una ocasión, para dilucidar la verdad en una disputa, fue necesatio traer de su biblioteca, un libro de Plinio, del que un fraile jerónimo tradujo un texto para aclarar la cuestión:

«Llegaua con esto la hora de comer, y entretanto que comia, se holgaua que el Medico Matisio y Guillelmo Malineo disputassen alguna cosa, que entrambos eran hombres doctos, y de buena leccion; y el Cesar procuraba hallar alguna ocasión, preguntandoles cosas naturales, propiedades de frutas, yerbas, plantas, y cosas desta suerte con que ponerlos en ruydo, porque aun aquel tiempo no fuesse sin prouecho ni solo para el cuerpo. Era amigo su Magestad de cortarse el mismo lo que comia, aunque ni tenia buenas ni desembueltas las manos, ni los dientes. En estas disputas sucedió vn dia que los dos se encontraton sobre vn lugat de Plinio, que tiene buena ocasion para estas dudas: para sentenciar el pleyto y saber quien tenia razon, mandó llamar a su Confesor fray Iuan Regla, que sabia bien la lengua latina, y aun Griega. Trajose vn Plinio, y diose la sentencia por Martisio, declarando doctamente el lugar el Confessor, de que recibio mucho gusto el Cesar»\$1.

81 SIGÜENZA, Historia de la Orden de San Jerónimo, op. cit., , p. 151. Siguienza copia esta anécdota de un manuscrito, que Sánchez Loro atribuyó a fray Hernando del Corral, y que con el título «Historia breve y sumaria de cómo el Emperador Don Carlos V, nuestro señor, trató de venirse a recoger al Monasterio de San Jerónimo de Yuste...", y que en la actualidad se encuentra en la sección de manuscritos varios en los Archives Générales du Royaume, en Bruselas, bajo la signatura $805 \mathrm{~A}-\mathrm{b}$. CADENAS Y VICENT, (Carlos de Habsburgo, op. cit., p. 64, n. 3) recoge la anécdota en la narración del manuscrito: «Mientras duraba la comida, disputaban el médico Mathisio y Guillermo Malineo, que ambos eran sabios y leídos, unas veces de hisrorias, otras de cosas de la guerra. $Y$ acaecióles una vez, 
Esta anécdota nos permite advertir que no debe olvidarse, al estudiarse el entorno librario de Carlos $\mathrm{V}$ en Yuste, que otras personas de su entorno más cercano tenían sus propias bibliotecas, de mayor o menor enjundia, e incluso no desmerecer la librería monástica de los frailes jerónimos. En más de una ocasión debí hacerse uso por parte del emperador de estos libros. Así sabemos, por ejemplo, que su confesor, fray Juan Reglá, solía leerle y comentarle tras la comida algunos pasajes de San Bernardo, o alguna epístola de San Jerónimo, con la que reflexionaban un rato y mantenían una "platica y conuersacion celestial ${ }^{82}$, autores de los que no tenemos constancia estuvieran contenidos entre los libros de su señor, y asimismo sabemos que Henry Mathise tenía una biblioteca en Yuste, compuesta de ejemplares latinos y griegos, y otros en lengua vernáculas, como también es posible que la tuviera van Male, un humanista. En este contexto, los horizontes intelectuales de Carlos V no deben considerarse basados en una lectura personal, sino también colectiva, en el que los libros no sólo pasaban de una mano a otra, sino que se comentaban y leían en amena tertulia o seria disputa teológica.

Estas aficiones, sin embargo, no distrajeron al monarca de su principal obsesión: la meditación sobre su vida. En Yuste continuó el dictado de sus memorias a Guillaume van Male. Para su redacción guardaba en su gabinete cesáreo la Guerra de Alemaña, en el manuscrito original que Luis de Ávila y Zúñiga, le entregó, probablemente hacia $1548^{83}$, y un ejemplar en italiano de los Comentarios de Julio César, probablemente en la traducción del genovés Agostino Ortica della Porta ${ }^{84}$. De esta obra se decía que era su libro de cabecera en campaña; en Yuste pasó a ser un modelo para sus memorias. Quizá también se sirvió el anciano monarca, para dicha redacción, de eçiertos cuadernos de florian do canpo y otros sobre historias que estauan enbueltos en vn paño», y que

sobre cierta autoridad de Plinio, tener cada uno de ellos el parecer contrario, afirmando uno una cosa y otro otra sobre el entendimiento della. Para lo cual mandó su majestad llamar al padre fray Juan Regla y que trujese de camino un Plinio, para que declarase quien tenía más verdadera opinión. Y venido el padre fray Juan Regla, sin saber qué opinión tenía uno, ni qué otro, fue del parecer y sentencia del filósofo Guillermo; con que su majessad quedó muy contento y le pareció que Guillermo Malineo tenía más razón que Mathiso.»

s2 SIGǗNZA, Historia de la Orden de San Jerónimo, op. cit., II, p. 152.

s3 Ávila y Zúníga, Luis de: Comentarios de la guerra de Alemaña becha por el emperador Carlos quinto contra los bereges $y$ Rebeldes, compuesto por don Luis de Cuñiga y Auila commendador maior de Alcantara. Códice en papel. Letra del siglo XVI a plana encera. $185 \times 145 \mathrm{~mm} .104$ hojas foliadas a lápiz con numeración arabiga. RBME, e-IV-1.Encuadernación tenacentista en cueto tojo con adornos y filetes dorados. Aunque en el inventario de Yuste no se cita que estuviera escrito a mano, tanto la dedicatoria a Carlos V, como la encuadernación, semejante a ottos libros que el monarca llevó al monasterio.

${ }^{84}$ Cayo Julio CÉSAR, COMMENTARII DI CAIO GIVLIO CESARE TRADOTTI IN VOLGARE PER AGOSTINO ORTICA GENOVESE. Nuouamente bystoriati. M. D. XXVII.. Venecia, Francesco Bindoni y Mafeo Pasini, 1528, $8^{\circ}$. Dedicatoria de Ortica a Ottaviano di Campo Ragoso, Duce de Génova, RBME, 60-IV-9. Encuadernación escurialense.

Hispania, LX/3, núm. $206(2000)$ 911-944 
en la actualidad resulta dificil de identificar con los fondos manuscritos de la Laurentina.

No olvidó tampoco el monarca su condición de caballero y maestre de la orden, casi mítica, del Toisón de Oro. En Yuste retuvo un manuscrito con los estatutos de la Orden, que creemos, se corresponde con el magnífico volumen de las Ordenanzas de la Orden del Toisón, en francés, que se conserva en el Instituto de Valencia de Don Juan. Podría haber dejado este magnífico libro en el castillo de Simancas, como parte del patrimonio regio, (al igual que dejó el pergamino con los caballeros de la Jarretera), pero Carlos seguía siendo caballero del Toisón, y nieto de dos grandes caballeros. Esta condición no se perdía, y los estatutos eran un símbolo de su pertenencia a la orden militar, tanto como el vellocino dorado colgado a su cuello. Recordemos que el emperador hacía decir muchas misas en Yuste, por su hijo, su padre, su madre su esposa, y otra en particular, una por los "caualleros del Tuson que morian»85. Se trata de la misma mentalidad caballeresca que encontramos tras el pergamino de las armas y nombres de los caballeros de la orden de Jarretera, guardado en Simancas, y precioso recuerdo de sus relaciones inglesas. Esta visión del mundo nunca le abandonó, como tampoco el recuerdo, a veces grato, pero en Yuste muchas veces doloroso, de su época dorada, magnífica, según le retratara Simón Benning en este libro de las Ordenanzas del Toisón, pero también cargada de errores, de pecados y de tareas inconclusas, sobre las que meditaba, recordaba y expiaba. iQué formidable constraste!, pero también, iqué pesada carga en las postrimerías de una vida! En esta última etapa, sólo los libros - no los Fugger, no los tercios, no Cobos, ni tampoca Gattinara-, pudieron ayudar Carlos V a sobrellevar tal peso.

85 SigüENZn, Historia de la Orden de San Jenónimo, op. cit., II, p. 152. 